\title{
Innate immune memory: An evolutionary perspective
}

\author{
Gourbal Benjamin 1, 3, ${ }^{*}$, Pinaud Silvain 1,6, Beckers Gerold J. M. 2, Van Der Meer Jos W. M. 3, 4, \\ Conrath Uwe ${ }^{2}$, Netea Mihai G. $3,4,5,{ }^{*}$
}

${ }^{1}$ Univ Montpellier, IFREMER, CNRS,Univ Perpignan, Interact Hosts Pathogens Environm UMR 5244,

Perpignan, France.

2 Rhein Westfal TH Aachen, Dept Plant Physiol, Aachen, Germany.

${ }^{3}$ Radboud Univ Nijmegen, Med Ctr, Dept Internal Med, Nijmegen, Netherlands.

${ }^{4}$ Radboud Univ Nijmegen, Med Ctr, Radboud Ctr Infect Dis, Nijmegen, Netherlands.

5 Univ Bonn, Life \& Med Sci Inst LIMES, Dept Genom \& Immunoregulat, Bonn, Germany.

${ }^{6}$ Welcome Trust Sanger Inst, Hinxton, England.

* Corresponding authors : Benjamin Gourbal, email address : benjamin.gourbal@univ-perp.fr ; Mihai G. Netea, email address mihai.netea@radboudumc.nl

\begin{abstract}
:
Over the last decades, there was increasing evidence for the presence of innate immune memory in living organisms. In this review, we compare the innate immune memory of various organisms with a focus on phylogenetics. We discuss the acquisition and molecular basis of immune memory and we describe the innate immune memory paradigm and its role in host defense during evolution. The molecular characterization of innate immunological memory in diverse organisms and host-parasite systems reconciles mechanisms with phenomena and paves the way to molecular comprehension of innate immune memory. We also revise the traditional classification of innate and adaptive immunity in jawed vertebrates. We emphasize that innate immune responses have the capacity to be "primed" or "trained", thereby exerting a yet unknown type of immunological memory upon re-infection.
\end{abstract}

Keywords : defense priming, evolution, innate immune memory, invertebrates, plants, trained immunity, vertebrates 


\section{I E VOLUTIONARY SUCCESS OF INNATE IMMUNE MEMORY}

All living organisms face biotic and abiotic stress in their environments. Pathogens for example cause substantial deleterious effects on their hosts, and thus represent a major driving force for host evolution.1 Interactions between hosts and pathogens are thus dynamic biological systems in which the host's defense mechanisms face the pathogen's infectivity mechanisms.2,3 Therefore, all living organisms have evolved defense systems capable of recognizing and control/contain and/or eliminate most of the pathogens encountered during their life span.4,5 In vertebrates, adaptive immunity is considered as the ultimate outcome of this evolution. Therefore, when considering immunological memory as an important survival trait, it is difficult to envision that immune memory evolved only in vertebrates, which represent only about $1 \% 6$ of all living species (Figure 1). Moreover, immunological memory within the vertebrate lineage evolved not just once, but twice. First, jawless vertebrates have evolved an alternative antigen recognition system, the variable lymphocyte receptor (VLR) via somatic gene assembly comprising leucinerich repeat (LRR) motifs.7 Second, cartilaginous, bony fishes (jawed fish), amphibians, reptiles, birds, and mammals developed the major histocompatibility complex, T-cell receptors, and Bcell receptors (immunoglobulins) as an adaptive Ig-based memory.7

An evolution of immunological memory solely in vertebrates,8,9 but no in other metazoans, makes little evolutionary sense considering the evolutionary success of adaptive immunity-free organisms that represent $99 \%$ of the total Earth biodiversity (Figure 1). Indeed, plants and invertebrate organisms are also confronted with environments full of complex changing populations of microorganisms and potential pathogens, engendering selective pressures similar to those experienced by vertebrates.2,8,10,11 Therefore, one can expect that plants and invertebrates should also possess mechanisms to adapt their host defense for the interaction with these pathogens. Over the past two decades, several interesting studies have provided evidence that the immune system of plants and invertebrates may be "primed" in a sustainable manner, leading to a protection against subsequent infections.12-14 Interestingly, these observations were re-inforced by the recent discovery of memory capacities for the innate immune system of vertebrates that reacts in an adaptive manner to secondary infections, a process that has been termed "trained immunity".15 Memory of innate immune responses evolved from ancient precursors and still plays a vital and basic role even in vertebrates in which adaptive characteristics are prominent.16

\subsection{A complex terminology for a simple phenotype}

The immune response of living organisms traditionally group into innate and the adaptive immune responses, the latter exclusively expressing exquisite specificity. This paradigm of differential presence of adaptation (memory) in innate vs adaptive immunity has been challenged recently by the discovery in different phylogenetic groups of a new aspect of immunological memory also in the innate immune system.12-15,17

In these organisms, the demonstration of a memory response of the innate immune defense system remains very elementary. It has been shown that following a first encounter with a pathogen, the innate immune system acquired new capacities that protect the organism against further infection with related or unrelated pathogens.13,18-20 A growing number of studies have reported memory properties of innate immune responses throughout invertebrate phylogeny. Microbiota induce an innate immune memory response to protect mosquitoes from Plasmodium, 21 the buff-tailed bumblebee (Bombus terrestris) displays innate immune memory against different pathogens, 22 the tapeworm Schistocephalus solidus induces immune memory in the copepod crustacean, 23 and the fresh water snail Biomphalaria glabrata possesses a complex immune memory responses against the agent of human schistosomiasis. 24 
Consistently, multiple studies disclosed that plants, which lack mobile immune cells and the bona-fide adaptive immune system, upon recognition of infectious microbes build immunological memory 12 that enables a boosted defense response on re-infection.

In addition to the studies in invertebrate animals and plants, there is a growing body of evidence for innate immune responses in vertebrates also exhibiting adaptive characteristics.15,25 It is therefore reasonable to conclude that immunological memory is a general characteristic of the entire living kingdom.12,13,15,26 However, the main challenge encountered in the literature is the heterogeneity of experimental models and protocols used to demonstrate the existence of innate immune memory.13 The diversity of approaches causes confusing terminology: innate immune memory has been described as acquired/inducible resistance, protection, sustained immune responses, and has been designated as "immune priming" or "innate immune memory" for invertebrates.13 In plants, "defence priming" (a state of alert that represents immunological memory) was associated mainly with plant immune responses termed "Systemic Acquired Resistance" (SAR),14 "Induced Systemic Resistance" (ISR),27 and $\beta$-aminobutyric acid-induced resistance (BABA-IR).28 SAR is induced by necrotizing plant pathogens, 29 whereas ISR is activated by beneficial rhizobacteria and rhizofungi.27 BABA-IR is activated by the non-protein amino acid BABA.30 Finally, in vertebrates the innate immune memory response was termed "trained immunity".31 Moreover, when pathogens were not totally eliminated by the innate immune recall response, but the host rather adapts to limit tissue damage upon infection with the invading "microorganisms", one additional term process has been used, the innate immune tolerance. 32

An important aspect of immune memory is specificity, which may be considered a hallmark of classical adaptive immune memory. Indeed, vertebrates possess an extraordinary system able to somatically generate an exceptional diversity of antigen- specific receptors,33-35 in which a set of gene segments is randomly assembled during lymphocyte ontogeny to generate diverse receptors. 36

This adaptive immune system can recognize most pathogens and/ or antigens and initiate a protective response. Gnathostomes and Agnathans seem to generate a highly diverse repertoire of lymphocytes, each bearing a different cell surface antigen receptor.37,38 The interaction of lymphocyte receptors with antigens triggers signal transduction, eventually leading to an effector phase that neutralizes or destroys the pathogen/antigen. These diversified immune receptors can differ between vertebrate lineages. In Gnathostomes, they are members of the immunoglobulin superfamily for B- or T-cell receptors, whereas in Agnathans, they are members of the LRR or VLR families. Regardless of that, however, they are generated through recombinatorial processes that occur somatically during lymphocyte differentiation and proliferation. In all vertebrates, these genes have undergone convergent evolution leading to a vast repertoire of somatically generated receptors, proving the high selective value of this mechanism in vertebrates and suggesting that it might be found elsewhere.

Until recently, such highly variable receptors have not been identified in Agnathans, or in Deuterostome or Protostome invertebrates.39 However, some immune receptors belonging to invariable germline-encoded factor of Pathogen-recognition receptor (PRR) and other effector molecules are able in these phyla to recognize antigens with an apparently low specificity. These PRRs are believed to recognized a limited set of microbial antigens via their PAMPs to limit pathogen invasion. 40 However, recent reports have challenged this paradigm by revealing the existence of diversified immune receptors in several invertebrates. These receptors can be somatically diversified in a manner similar to vertebrate immunoglobulins or $\mathrm{T}$ and $\mathrm{B}$ cell receptors (ectopic recombination and hot spots of mutations) but are not associated with clonal cell selection. These studies indicated the existence of polymorphic and/or diversified putative 
immune receptor variants that vary considerably between individuals, yielding an enlarged repertoire of putative recognition molecules. These diversified and somatically generated receptors have been identified in echinoderms (SRCR or Sp185/333 of sea urchin 41), insects (Dscam of Drosophila melanogaster and Anopheles gambiae42,43), crustaceans, 44 and mollusks (FREPs of Biomphalaria glabrata45).

Invertebrates possess sophisticated recognition systems for dealing with pathogens. One can speculate that large and individual repertoires of immune receptors might confer the specificity of invertebrate immune systems. New results suggest that polymorphic set of canonical immune sensors (PRRs) must be supplemented by non-canonical immune sensors such as actin and collagen 46 or enzymes like GAPDH and $\alpha$-amylase.47 Such non-canonical immune sensors enlarge immune sensor factors and thus increase the PRR repertoire that participates in pathogen recognition. It has been proposed that such PRRs possessed the ability to combine each other into multiheteromeric complexes to generate an enhanced capacity of pathogen sensing in invertebrate organisms.47,48 Indeed, specific recognition has been observed in experiments dedicated to self vs non- self discrimination in invertebrates. Early studies of graph rejection constitute examples of allorecognition in diverse invertebrate phyla (Porifera, Cnidaria, Annelida, Echinodermata).26,49-52 It can be speculated that this specific recognition has evolved not only from the identification and control of self-aberrant cells by the immune system, but also as a specific defense against pathogens.19 If invertebrates possess diversified immune receptors involved in the specific recognition of pathogens, it is realistic to envisage that they can also adapt after infection, a de facto immune memory, especially for long-lived species that might encounter the same pathogens on multiple occasions. Indeed, several lines of evidences supporting such memory have been reported in invertebrates (see 19,21-23,53 for details).

Different from jawed vertebrates, plants evolved neither mobile immune cells nor an adaptive immune system. They rather possess a multilayered immune system of constitutive (eg, the waxy cuticle or corky periderm atop their shoot) and inducible defense responses. The activation of inducible plant defense is triggered, for example, on activation of cell surface-localized PRRs by evolutionary conserved PAMPs. This rather unspecific type of inducible plant immune response is referred to as PAMP-triggered immunity (PTI) or microbe-associated molecular pattern (MAMP)-triggered immunity (MTl; because not all microbes are pathogens). One of the most prominent examples of PAMP/PRR interaction in plants is the activation of the LRR receptor kinase (LRR-RK) FLAGELLIN-SENSING2 (FLS2) by bacterial flagellin.54,55 FLS2 recognizes a Nterminal, immunogenic epitope of 22 amino acids in flagellin, referred to as flg22.54,55 Upon recognition of flg22, FLS2 recruits BAK1, a LRR-RK that acts as aco-receptor for flg22. This then leads to full activation of flg22-triggered immunity.56 Other prominent PAMP/PRR pairs with a role in plant immunity are the bacterial elongation factor Tu (EF- Tu)/EFR (another LRR-RK duo), the fungal chitin/CERK1 (in the thale cress reference plant Arabidopsis thaliana, subsequently referred to as Arabidopsis) and the bacterial lipopolysaccharide (LPS)/ LORE, chitin/CEBiP (in rice) pairs.56,57 PTI is unspecific in that it typically fends off multiple microbes, whether infectious or not, likely because of the conserved nature of PAMPs across diverse species, genera, families, orders, and even classes of pathogens.4,58

Another type of inducible plant immunity is based on the direct or indirect recognition of pathogen effectors, previously called avirulence (Avr) proteins, by appropriate plant resistance ( $R$ ) proteins. The interaction of effectors with $R$ proteins leads to so-called gene-forgene immunity.59,60 In the indirect recognition of pathogen effectors, watchdog R proteins guard the integrity of cellular proteins, and when they sense modification or degradation of these proteins by appropriate pathogen effectors, they will initiate plant defence.61-64 
No matter whether pathogen effectors are recognized directly or indirectly, their perception is very specific and leads to effectortriggered immunity (ETI). ETI is highly robust and often associated with a localized programmed cell death response called the hypersensitive response (HR).65-67 The HR is assumed to prevent the spread of biotroph pathogens to the healthy tissue. PTI and ETI are both associated with complex defense signaling which includes the release of reactive oxygen species (ROS), mitogen-activated protein kinase (MPK) activity, plant hormone synthesis and function, metabolic changes, excessive transcriptional reprogramming, and the synthesis and accumulation of defensive secondary metabolites (so-called phytoalexins).62,68-70 PTI and ETI trigger very similar transcriptional reprogramming in the plant, independent of the origin of the MAMP or effector.71,72 However, the transcriptional ETI response typically is faster, stronger, and/or more prolonged than PTI-associated gene expression.68,69,71,73 Very recent studies suggested strong similarity of defense responses associated with PTI and ETI in both animals and plants. Although in plants ETI is known since many years, studies in the animal field just recently provided some mechanistic insight into ETI in animals.60,74-79 Despite many similarities in the defense responses associated with PTI and ETI in animals and plants, the latter do not possess classical adaptive immunity. The lack of an adaptive immune response likely forced plants to evolve a multiplicity of PRRs, whereas animals elaborated fewer PRRs for recognizing PAMPs.56,76 Both PTI and ETI can activate SAR (see Box 1). The systemic immune response is characterized by its capacity to memorize previous infection 12,14 and by its broadspectrum of activity to microbial pathogens.29 Both these characteristics also mark ISR, which is promoted upon colonization of plant roots with beneficial rhizobacteria and rhizofungi (see Box 1).27 Whereas SAR wards off mainly biotroph pathogens, ISR is typically effective against necrotrophic plant pathogens. 27

In vertebrates, trained immunity has been defined as the epigenetically driven rewiring of the transcriptional programs of innate immune cells, leading to an enhanced antimicrobial response.80 At the level of myeloid cells such as monocytes and macrophages, exposure to certain microbial components (eg, beta-glucan) or vaccination (eg, with bacilli Calmette-Guerin, BCG) leads to changes in chromatin architecture as revealed by genome-wide changes in histone marks such as H3K4me1, H3K4me3 and H3K27Ac.81 These changes are accompanied by increased cytokine production upon re-stimulation: this response is essentially non-specific to heterologous stimuli and infection. Subsequently, a large number of epidemiological studies have demonstrated that certain vaccination such as bacilli CalmetteGuerin (BCG), measles or oral polio vaccine lead to protection against heterologous infections.82 Interestingly, while memory characteristics have also been clearly demonstrated for NK-cells as well, in their case a specificity of the response independently of classical gene recombination mechanisms has been reported: after murine cytomegalovirus ( $\mathrm{mCMV}$ ), induced NK memory appears to protect against $\mathrm{mCMV}$ but not against the related virus EBV.83 At the same time there was impaired heterologous immunity against influenza and L. monocytogenes. 84,85 After mCMV infection, NK cells bearing the virus-specific Ly49H receptor proliferate 100 -fold in the spleen and 1,000fold in the liver after infection.86 Additional evidence for the specificity of NK-induced memory is represented by the identification of antigen-specific memory toward haptens, 85 with CXCR6positive NK-cells in the liver reported to mediate these specific responses. $85 \mathrm{All}$ in all, these data suggest that the mechanisms involved in NK-mediated innate immune memory are complex and involve both specific and non-specific effects. The precise mechanisms that mediate the specificity of NK cell memory responses in vertebrates remain however to be fully deciphered.

Would specificity of innate immune memory in invertebrates and plants be an ancestral character that has been secondary partially hidden or lost in Gnathostomes that were the first to supplement innate responses with adaptive elements? Did variable lymphocyte receptors as LRRs or T-cell 
and B-cell receptors represent additional highly specific adaptive weapons while assisting innate response results in the loss of innate immune memory specificity?

These questions show how delicate it is to come up with a universal definition of innate immune memory. However, the overall definition of the phenotype should be simple: a partial or total resistance upon re-exposure to pathogens, that can be either specific or not, supported by the innate immune system. Deciphering the cellular and molecular basis of immune responses from an increasing variety of phylogenetically distant models will shed light on the nature and origin of these evolutionary innovations, including different types of immune memory.

\subsection{Innate immune cells, the ancestral support of innate immune memory}

Host responses against invading pathogens are mainly linked with cellular response activation. Since the appearance of the first eukaryotic cells, defense mechanisms have evolved to secure cellular integrity, homeostasis, and so survival. For example, unicellular amoebae developed the ability to phagocyte foreign material as a part of their food uptake mechanisms. 87 This basic phagocyte function is conserved in higher plants, invertebrates and vertebrates. 88 Interestingly, it is now clearly demonstrated that innate immune cells are highly conserved among vertebrates and various invertebrate phyla.8,88 In the lower deuterostome (echinoderms, hemichordates, urochordates) as well as in the cephalochordates, hemocyte classes with characteristics very similar to those of lophotrochozoans and ecdysozoans have been reported.88 Even if those cells have been named differently (amebocytes, hemocytes, coelomocytes, granulocytes, monocytes, macrophages), they have basically a macrophagelike appearance and have, to a certain extent, similar phagocyte functions. 8 The main function of these cells is based on autonomous recognition of self or non-self, allowing the host organism to bind, engulf or encapsulate, and eliminate self-aberrant cells or foreign pathogens. This basic phagocytic ability is shared from unicellular and most groups of multicellular (porifera, cnidarians, annelids, arthropods, mollusks, echinoderms) to vertebrate organisms.8,89 This has led to a renewed interest regarding homologies between innate immune cell types and their developmental origin, believe to diverge from a common type of progenitor cell, the hemocytoblast among vertebrates and invertebrates alike. 88

Interestingly, plants lack specialized mobile immune cells. Instead, every plant cell is thought to be capable of launching an effective immune response. This observation prefers convergence rather than conservation in the evolution of the immune systems of plants and animals.

The presence of immune memory characteristics in innate host defense of plants and different animal lineages suggests that innate immune memory should be an ancient trait that appeared early in evolution or is the result of convergent evolution or homoplasy. Recent findings strongly suggest that the molecular pathways involved in the development and function of innate immune cells are highly conserved among vertebrates and various invertebrate phyla. These assumptions open the way to hypothesis and identify similar ancestral mechanisms and genes shared by living organisms. Capabilities given by such innate immune cells would be conserved in the evolutionary time scale. It is thus likely to suggest that memory characteristics of innate host defense in mammals would have similar molecular support in the plant and/ or animal lineages.

\section{2 | TOWARD A UNIF YING MODEL FOR INNATE IMMUNE MEMORY}

When trying to understand the evolution of innate immune memory, a logical start point may be that every living organism, which displays an acquired resistance or innate immune memory capacity, is likely to share common molecular features of their immune response that represents the basis of innate immune memory. However, the presence of clonal selection, antibodies, or mobile immune-specialized cells is not universal in the living kingdom. 
To defend against pathogens, hosts activate a wide range of immune responses aimed to clear the exogenous intruder. If these pathogens were being met again in the future, expression of the same wide range immune response would be expected to eliminate it. This can be attained only if the host was able to conserve a trace of the first encounter with the pathogen and thus activate the best-adapted response to clear it. Remembering the previous encounter with a pathogen would thus be the best way to clear a pathogen attack at lower cost. While immune memory can thus be easy understood, the pattern of immune memory can be far different depending of the host or pathogen concerned. Sustained response (Box 1) may seem the simplest way to attain long-time resistance, but this approach may be very costly.90 After it has select the best way to clear the pathogens, like an antimicrobial peptide or a toxin,91,92 host can conserve a high level of expression for this immune weapon from very long time93 up to the whole lifespan.94

To save costs and side effects associated with the auto-immunity induced by the high expression of an immune response, evolution has selected another way to produce an immune memory response. Following the first encounter with a pathogen, a generalized immune response is produced up to the clearance of the pathogen. If hosts can then develop an immune memory response, the information how to deploy efficiently key factors needed to clear the pathogens can be saved in memory to be used later when a secondary encounter occurs. Following the secondary encounter, the enhanced features selected by the primary encounter are employed both more rapid and stronger, leading to a very efficient elimination of the pathogenic agent. From bacteria kingdom to plants and animals, even to vertebrates, all living organisms display their own ways of acquired innate immune resistance after a primary exposition to a pathogen.

\section{1 | Molecular events associated with innate immune memory in prokaryotes (Figure 2)}

Prokaryotic organisms face an enormous diversity of pathogens in their environments and have developed distinct defense strategies, including innate immunity; recall immunity; and dormancy induction, or programmed cell death. In bacteria and archaea, numerous studies have discussed clustered regularly interspaced short palindromic repeats (CRISPR)-cas-associated genes as an adaptive immunity system that functions via a distinct endogenous-exogenous genome recognition mechanism that is partially similar to the mechanism of eukaryotic RNA interference (RNAi).94-97 Upon viral injection, the CRISPR-cas system incorporates a small sequence of the viral genome or plasmid DNA into the CRISPR repeat cassettes and employs the processed transcripts of these spacers as guide RNAs to cleave the cognate foreign viral DNA or RNA by cas nucleases.95 The CRISPR-cas system is considered to be an adaptive immunity or immunization process.94-97 This immunization through spacer acquisition enables a unique form of evolution whereby a population not only rapidly acquires resistance to its pathogens but was also able to transfer this resistance mechanism vertically to its progeny. 97

\section{2 | Molecular events associated with innate immune memory in vertebrates (Figure 2)}

Important clues that vertebrate innate immunity has adaptive characteristics can be found in experimental studies in mice. A large number of such studies, both old and new, have shown that priming or training mice with microbial ligands can protect against lethal infection. For example, trained immunity induced by $\beta$-glucan (derived from fungi) induces protection against bacterial infection with Staphylococcus aureus. 98 Similarly, the bacterial peptidoglycan component muramyl dipeptide induces protection against Toxoplasma, 99 and CpG oligodeoxynucleotide administration protects against sepsis and Escherichia coli meningitis.100 Furthermore, flagellin from gram-negative bacteria can induce protection against the grampositive bacterium Streptococcus pneumonia101 and rotavirus,102 independent of adaptive 
immunity and induced by dendritic cell-derived IL-18, which drives production of IL-22 from epithelial cells. In addition to microbial ligands, there is evidence that certain proinflammatory cytokines may induce trained immunity: injection of mice with one dose of recombinant IL-1 3 days before an infection with Pseudomonas aeruginosa protected the mice against mortality.103 The non-specific character of trained immunity argues against a classical memory effect mediated by adaptive immunity, and suggests activation of non-specific innate immune mechanisms.

The molecular basis of vertebrate innate immune memory has been only partially defined, but this likely includes multiple regulatory layers related to chromatin organization and the persistence of microRNAs (miRNAs) induced by the primary stimulus. Upon primary stimulation of myeloid cells, a significant gain in accessibility, increased acetylation, and RNA polymerase II recruitment result in the activation of gene expression hundreds of times higher than baseline in a short window of time. These changes are driven by the recruitment of stimulation-responsive transcription factors (eg, NF-KB, AP-1, and STAT family members) to enhancers and gene promoters.104 Maintenance of such enhanced accessibility underlies the more efficient induction of genes 'primed' or 'trained' by the initial stimulation.105 It has been shown that histone modifications are specifically bound by recognition domains contained in various proteins implicated in transcriptional control (eg, the bromodomainacetyl lysine interaction),106 and the persistence of histone modifications deposited at promoters or enhancers after the initial stimulus is thus impacting the secondary response. 31

One interesting paradigm is provided by latent or de novo enhancers,107,108 which are genomic regulatory elements that are unmarked or lowly marked in unstimulated cells but gain histone modifications characteristic of enhancers (such as monomethylation of histone H3 at K4, H3K4me1) only in response to specific stimuli. In vitro, upon removal of the initial stimulus, a fraction of latent enhancers retains their modified histones and can undergo a stronger activation in response to re-stimulation. Recent studies have investigated epigenetic changes in vertebrate immune cells during induction of trained immunity. One early study proposed that changes in epigenetic status underlie the repression of inflammatory genes during LPS tolerance in mammalian cells, whereas genes mainly involved in antimicrobial responses were not affected or even increased.105 Similarly, exposure of monocytes/macrophages to Candida albicans or $\beta$ glucan modulated their subsequent response to stimulation with unrelated pathogens or PAMPs, and the changed functional landscape of the trained monocytes was accompanied by epigenetic reprogramming.31,81 Activation of trained immunity in mammalian myeloid cells is accompanied by increased markers of open chromatin such as H3K4me1, H3K4me3, and $\mathrm{H} 3 \mathrm{~K} 27 \mathrm{ac}, 81$ whereas the repressor chromatin mark H3K9me was decreased. Pathway analysis identified important immunological (cAMP-PKA activation) and metabolic (aerobic glycolysis) pathways that play crucial roles in induction of trained immunity. 81 In addition, both LPS and beta-glucan induce innate immune memory through a MAPK-dependent pathway that phosphorylates ATF7, subsequently reducing the repressor mark H3K9me2.109 Recently, changes in DNA methylation have been also reported after BCG vaccination.110 Changes in noncoding RNAs have been also suggested to affect trained immunity, but this remains to be demonstrated.

Compelling evidence that trained immunity may mediate at least some of the protective effects of vaccination has come from studies showing that vaccination of animals with bacillus Calmette Guerin (BCG), the tuberculosis vaccine that is also the most commonly used vaccine worldwide, induces T-cell independent protection against secondary infections with $\mathrm{C}$. albicans or Schistosoma mansoni. 111,112 These data are complemented by studies investigating the mechanism of protection against disseminated candidiasis conferred by attenuated strains of $C$. 
albicans. For example, when an attenuated PCA-2 strain of C. albicans that is incapable of germination is injected in mice, protection is induced against the virulent strain CA-6.113 Importantly, this protection was also induced in athymic mice and Rag1-deficient animals, demonstrating a T-cell independent mechanism.31,114 In contrast, the cellular substrate of the protection against re-infection in these models was dependent on macrophages113 which had an increased pro-inflammatory cytokine production,115 both prototypical innate immune components. Extensive studies have explored the molecular mechanisms that enable myeloid cells to display memory characteristics. Inductions of immunological signals through patternrecognition receptors such as TLRs, C-type lectin receptors or NOD-like receptors induce metabolic and especially epigenetic rewiring of innate immune cells ;

In addition, some viral and parasitic organisms can also exert protective effects through mechanisms independent of adaptive immunity. Herpes virus latency increases resistance to the bacterial pathogens Listeria monocytogenes and Yersinia pestis, 116 with protection achieved through enhanced production of IFN $\gamma$ and systemic activation of macrophages. Similarly, infection with the helminthic parasite Nippostrongylus brasiliensis induces a long-term macrophage phenotype that damages the parasite and induces protection from re-infection independently of T and B lymphocytes.117

Although macrophage-dependent secondary protection from infection is apparently non- specific, natural killer (NK) cell-mediated immune memory may provide increased specificity. Consistent with this idea, several recent studies have reported that NK cells develop adaptive immune characteristics after infection with mCMV.86,118- 120 After infection, NK cells bearing the Ly49H receptor proliferate, and these cells persist in lymphoid and non-lymphoid organs during the contraction phase of the NK cell response. Upon re-infection, these "memory" NK cells undergo a secondary expansion, rapidly degranulating and releasing cytokines, thus inducing a protective immune response. 86 Interestingly, it has been also recently shown that NK-cells can prime monocytes in the bone marrow during infection.121 A number of possible mechanisms have been put forward to explain the memory properties of NK cells, involving either the IL$12 /$ IFNY axis 120 and the activation of the co-stimulatory molecule DNAM-1 (DNAX accessory molecule-1, CD226).122

\subsection{Molecular events associated with innate immune memory in plants (Figure 2)}

Accumulation of PRRs and dormant signaling proteins. The plant hormone salicylate and its synthetic analogue benzothiadiazole (BTH) both activate defense priming (the seeming plant equivalent of trained immunity) and SAR in plants.123,124 In Arabidopsis, treatment with BTH enhances the level of FLS2 and its co-receptor BAK1 in microsomal preparations associated with enhanced responsiveness of the plants to flg22125. The BTH-primed plants also have higher levels of the chitin receptor and peptidoglycan co-receptor kinase CERK1.126 These findings provide a possible explanation for why primed plants express enhanced defense and broad-spectrum immunity upon perception of diverse PAMPs. Consistently, when compared to wild-type plants the priming-deficient ald1 mutant of Arabidopsis has reduced FLS2 and BAK1 levels and is more susceptible to infectious Pseudomonas bacteria.127 Therefore, defense priming and SAR are associated with enhanced PRR and co-receptor levels and PRR and co-receptor reduction attenuates plant immunity

A previous hypothesis proposed that defense priming involved accumulation of dormant enzymes with importance to cellular signal amplification.12 In Arabidopsis, perception of flg22 by FLS2 activates a mitogen-activated protein kinase (MPK) cascade that presumably is composed of MPK kinase kinase MEKK1, MPK kinases MKK4/5, and MPK3/6.128-132 Because the cascade serves to amplify the flg22 signal, MPK3/6 and other cascade members represent excellent 
candidates for cellular signaling enzymes that mediate defense priming. In 2009, Conrath et al123demonstrated that in Arabidopsis, defense priming leads to an enhanced cellular level of MPK3/6 mRNA transcript and protein. MPK3/6 is still kept inactive in primed cells but is readyto-go on re-challenge. Upon re-infection, more MPK3/6 proteins were activated in primed when compared to unprimed plants and this was associated with enhanced defense and systemic immunity. Accumulation of inactive protein in Arabidopsis leaves with systemic immunity was also reported for NPR1, a key immune regulator in plants.29,133,134 Thus, the accumulation of dormant PRRs, MPK3/6, NPR1, and probably other proteins important to cellular signaling seems to provide a memory to previous infection by priming the cell for enhanced defense and immunity.123,135 Consistent with this hypothesis, priming and systemic immunity were reduced or absent in the Arabidopsis mpk3, mpk6, npr1, and ald1 mutants with reduced levels of MPK3, MPK6, NPR1, or ALD1, respectively.123,127 Thus, accumulation of PRRs and latent cellular signaling enzymes seem to mediate defense priming in plants.

\subsection{1 | Chromatin dynamics}

Chromatin remodelling and modification or replacement of histone control gene transcription in all eukaryotes.136-138 In plants, these events control flowering time and organ development.139 In the last few years, it became evident that histone modification, histone replacement, and chromatin remodelling can provide a memory that augments the later transcription of genes,137,140 including those with a role in defense and systemic plant immunity. Access of the transcriptional machinery to DNA is regulated by nucleosome positioning and chromatin architecture.141 In fact, DNA and histones can both become covalently modified. Cytosine bases in DNA can be methylated, and this typically attenuates transcriptional activity, whereas the Nterminal histone tails can be subject to various post-translational modifications, which include acetylation and methylation.140,142,143 It is generally accepted that the pattern of histone modifications in the $5^{\prime}$ leader sequence and coding region of a given gene and their spatial relationship defines chromatin structure and transcriptional competence of that specific locus.144-146

Unfortunately, the role of most histone modifications in transcriptional regulation is unclear, as is the identity of enzymes that write, read, or erase a given modification. However, it is generally accepted that acetylation of histone lysine residues lacks the interaction of nucleosome neighbors, loosens the ionic DNA-histone interaction, and provides docking sites for regulatory proteins with bromodomains (eg, transcription factor IID [TFIID] and the SWI/SNF chromatinremodelling complex).147,148 The so-called histone code also claims that modified histones recruit regulatory enzymes to discrete sites in chromatin.149 For example, histone acetylation seems to facilitate site-specific recruitment of the general transcription machinery, including TFIID, the SWI/SNF chromatin-remodelling complex and the RNA polymerase II (RNAPII) complex. Accordingly, in eukaryotes there is close correlation of histone $\mathrm{H} 3$ and $\mathrm{H} 4$ acetylation and gene transcription.147

The role of histone methylation in transcriptional regulation is less clear because lysine and arginine residues can be methylated. In addition, up to three methyl groups can stick to a same lysine residue.150,151 The closest correlation between histone methylation and gene transcription was shown for tri-methylation of lysine 4 in histone $\mathrm{H} 3(\mathrm{H} 3 \mathrm{~K} 4 \mathrm{me} 3)$ in the promoter and coding region of gene.152 In 2007, H3K4me3 was uncoupled from PR1 defense gene transcription in Arabidopsis.153 H3K4me3 has instead been associated with a permissive state of PR1 transcription. The authors assumed that this was to prepare for rapid changes in gene transcription in times of stress.153 Another study revealed that in Arabidopsis priming the promoter of the defense-related transcription factor gene WRKY29 by BTH is associated with 
H3K4me3, H3K4me2, and acetylation of H3K9 (H3K9ac), H4K5ac, H4K8ac, andH4K12ac.154 Yet, these modifications did not activate WRKY29 until the plants were re-challenged [171]. Thus, specific histone marks that have been associated with gene activity are induced during defense priming before actual gene transcription.153,155 Similar observations were made for the related defense genes WRKY6 and WRKY53 in Arabidopsis.154 Together the findings demonstrated that priming certain WRKY genes for enhanced transcription involves histone modifications on the gene promoter that seems to facilitate WRKY gene transcription on rechallenge. These promoter histone modifications could either slack the interaction of nucleosome neighbors, loosen the ionic DNA-histone interaction, destabilize chromatin structure, and/or provide docking sites for transcription co-activators, chromatin-remodelling factors, and other effector proteins in chromatin.148,156-158 Together these processes could facilitate recruitment of components of the transcription pre-initiation complex and/or the general transcription machinery (eg, the RNAPII complex, TFIID), thus supporting transcription initiation and gene transcription. In a bona-fide SAR experiment localized inoculation of Arabidopsis leaves with infectious Pseudomonas in systemic leaves primed WRKY6, WRKY29, and WRKY53 for enhanced transcription upon re-infection.154 The systemic WRKY6/29/53 priming was associated with enhanced $\mathrm{H} 3 \mathrm{~K} 4 \mathrm{me} 3$ and $\mathrm{H} 3 \mathrm{~K} 4 \mathrm{me} 2$ on the WRKY6/29/53 promoters and with augmented $\mathrm{H} 4 \mathrm{~K} 5 \mathrm{ac}, \mathrm{H} 4 \mathrm{~K} 8 \mathrm{ac}$, and H4K12ac on the promoter of WRKY29. These histone marks were induced in the systemic leaves after local infection but before re-challenge.154 Thus, it seems that information about the localized infection is spread throughout the plant and stored as modification to histones on the promoter of defense genes in systemic leaves. Hence, primingassociated chromatin modification seems to provide a memory for priming in the systemic plant immune response. Correlation of WRKY29 priming and promoter H3K4me3 in various Arabidopsis mutants pointed to this particular histone mark as being important to WRKY priming and systemic immunity in this species of plant.154

\section{4 | Molecular events associated with innate immune memory in invertebrates (Figure 2)}

Despite accumulating phenotypic evidence of innate immune memory in invertebrates, knowledge of its mechanistic underpinnings is currently very limited. Invertebrate immune memory was believed to rely on two main processes: (i) a sustained response, involving the long-lasting upregulation of the same immune effectors after an initial immune challenge; or (ii) a recalled response, involving the activation and clearance of the immune response following a first encounter and neutralization of a pathogen and the faster and stronger activation of the same immune defense compounds in response to a secondary encounter.17 Interestingly a new and unexpected regulatory process has been described recently for invertebrates. Two recent studies reveal that the primary and the secondary immune responses, developed against the same parasite, involve different immune effector systems resulting in a transcriptional shift.17,24,159 This transcriptional shift was highlighted in mollusk and insect and involved a substantial set of differentially expressed transcripts that were over or under-represented exclusively following the secondary immune challenge. In Biomphalaria snails, this immune shift will changed the immune cellular encapsulation response toward a humoral immune response24 while in the coleopteran Tribolium, immune shift results in an enhanced pleiotropic immune capabilities.159

These studies evidence a so-far unreported process of immune memory response in invertebrates. Hemocytes can acquire a new phenotype toward a previously encountered pathogen, in anticipation of potential secondary encounter. In invertebrates, the activation of a subset of hemocyte immune cells was expected to be the main support of innate immune memory. Following infection by a virus, a bacteria or a protozoa, insects are able to select and activate a 
competent subpopulation of cells with enhance capacities of lysis or phagocytosis.21,160,161 Hemocytes in Drosophila acquire their function through multistep events of differentiation, which involve the regulatory interaction of evolutionarily conserved transcription and epigenetic factors.162 It is thus possible to imagine that such mechanisms would also occur in the acquisition of innate immune memory for invertebrates ;

The shift in gene expression demonstrates the activation of targeted transcript clusters exclusively following challenge, demonstrating a complex transcriptional reprogramming. We hypothesis, that this transcriptional reprogramming would be supported by an epigenetic reprogramming of hemocytes, based on remodelling of DNA methylation patterns, changes in histone marks, modifications of chromatin structure, or changes in miRNA, or IncRNA expression patterns.

Interestingly, it has been demonstrated that most of the invertebrates possess the epigenetic machinery needed to master physiological or biological life history traits including development, reproduction or immune response.163,164 Anopheles, for example, is able to regulate a microRNA aga-miR-305 to master the antiplasmodium response thanks to post-transcriptional modification of immune effector genes.165,166 Same results for other miRNA candidates were depicted following infection by metazoan 661 parasites in other invertebrate organisms.167169 These results of miRNA regulation for immune-related gene following infection probe the evidence that host can activate a complete new pathway to address a new pattern of response for a secondary challenge with pathogen. Concerning chromatin structure pattern and the associate histone mark modification, or DNA methylation patterns few evidences exist concerning their potential involvement in innate immune response.169-173

In vertebrates similar epigenetic and transcriptional reprogramming have been described for trained immunity.15,80,174 These changes are driven by the recruitment of stimulation-responsive transcription factors like NF-KB, AP-1, and STAT family members. It is to note that such major immune signaling pathways (ie, IMD, Toll, JAK/STAT, NF-KB) are also well conserved across invertebrate phyla 92,175-177 re-inforcing the chance to highlight an overall ancestral mechanism of innate immune memory from plants to vertebrates.17,159 Further research is now needed to test if whether epigenetic reprogramming appeared as an overall molecular process that can be found in invertebrates displaying innate immune memory phenotype

To summarize, vertebrate immunologists view immune memory as a property of lymphocyte populations that arise through gene recombination. However, this traditional view of immune memory would probably need to be rethinking with the help of plant and invertebrate immunologists, which showed that immune memory can be supported by innate immune cell populations and epigenetic reprogramming. Epigenetic processes appeared as the efficient mechanism of innate immune memory that is shared by distant phylogenetic phyla and involved in all processes of within generation of trained immunity (Figure 2). We defined innate immune memory as a more or less specific immunological memory resulting from rewiring the epigenetic program and the functional state of the innate immune cells, resulting in protection against secondary infections. Functional epigenetic reprogramming would thus be the main process for innate immune cells to acquire, store and recall new immune capacities. Would memory of the pathogen exposure be written in the epigenome?

\section{I INNATE IMMUNE MEMORY TRANSFER}

\section{1 | Cell-to-cell communication and systemic acquisition of memory phenotype}

An important aspect that deserves increased efforts in the coming years is to understand the intercellular dialogue, which is needed to spread the resistance signal from periphery throughout the entire host, to insure a systemic increase in the resistance to infection. 
These studies need to explain the mechanisms through which just few immune cells that encounter a pathogen could induce resistance of the entire metazoan organisms against already encountered intruders.

In vertebrates, little knowledge is available regarding the transfer of the innate immune memory. This is however extremely relevant, as these mechanisms are necessary to explain the strong nonspecific effects of vaccination. An important aspect to be considered regarding trained immunity induced in monocytes is the lifespan of these cells. Monocytes are cells with a short halflife in circulation, with recent studies suggesting it to be up to 1 day.178 The observation that trained monocytes have been identified in the circulation of BCG-vaccinated individuals for at least 3 months after vaccination179 suggests that reprogramming must take place at the level of progenitor cells of the innate immune cells as well. Indeed, recent evidence has emerged that innate immune memory can be transferred via hematopoietic stem and progenitor cells. Macrophages derived from hematopoietic stem and progenitor cells rendered tolerant by TLR2 exposure and transferred to irradiated mice retain a tolerant phenotype and produce lower amounts of inflammatory cytokines and reactive oxygen species.180 Similarly, beta-glucan induces trained immunity through effects on myeloid bone marrow progenitors.181 Furthermore, exposure of the skin of mice to UV radiation induces epigenetic reprogramming and a long-lasting effect on dendritic cell progenitors in the bone marrow that altered the function of their differentiated progeny.182 In addition, recent studies have suggested that microbiota can induce long-term functional reprogramming of bone marrow progenitors, and subsequently dendritic cells, to induce protection against Entamoeba histolytica.183 Which are the signals mediating the transfer of innate immune memory from the periphery to the bone marrow is not yet known in detail, although IL-1ß181,184 and GM-CSF 185 have been proposed as candidates. More studies are needed to understand in detail these processes.

In plants, various chemicals, amino acids, peptides and proteins were associated with systemic signaling in SAR, ISR, and BABA-IR. They comprise salicylate and methyl salicylate, 186 jasmonate 187 the dicarboxylic acid azelaic acid,188 the abietane diterpenoid,189 a glycerol-3-phosphate derivative,190 the predicted lipid transfer proteins DIR1, DIR1-like, AZI1, and its closest paralog EARLI1,191,192 the non-protein amino acids pipecolic acid127 and BABA,193 and monoterpenes.194 Many of these molecules are assumed to act in concert with salicylate when inducing SAR, and it seems that different combinations of these signals interact in the SAR response. Some of these signals seem to even serve as alarm signals between plants.194 Although jasmonate is likely involved in the systemic signaling of both SAR and ISR,187 the plant hormone ethylene was associated with systemic signaling only in ISR so far.195 Whether enhanced presence of PRRs, accumulation of dormant signaling enzymes, and modification to histones are induced by systemic signaling compounds other than salicylate and its biologically active analogues remains to be investigated.

In invertebrates, the sole example of systemic transfer of innate immune memory was demonstrated recently for Drosophila, in which a sophisticated systemic RNAi-based antiviral immunity mediated by hemocytes have been demonstrated.196 The fly use immune cells to generate immunological memory in the form of a stable systemic immunity, mediated by RNAi-containing exosomes.196 Except for this example, nothing else is known regarding the transfer or systemic acquisition of innate immune memory in invertebrates. However hemocyte-to-hemocyte communications following pathogen encounter have been described for numerous taxa.

The first pathway mediating cell-to-cell communication of immune information is microRNA (miRNAs). Many results were published on the role of small non-coding RNAs in the immunerelated gene regulation in insects, crustaceans and mollusks. In Anopheles gambiae miRNAs are involved in regulating the antiPlasmodium defence.165 
In crustacean miRNAs regulate innate immune response against bacteria in Procambarus clarkia197 and against white spot syndrome virus in shrimps.198 In the oyster Crassostrea gigas miRNAs were demonstrated to modulate immunity and regulate hemocyte migration.199 On the basis of these observations, we hypothesis, that miRNAs may be involved in systemic transfer of innate immune memory in invertebrates.

The second pathway mediating cell-to-cell communication of immune information in invertebrates is cytokines. Some families were identified 200 such as interleukins, Granulin, Macrophage inhibitory factor (Mif), Tumor Necrosis Factor (TNF),163,201-204 or alsoUpd2, Upd3, spätzle in Drosophila melanogaster,92 astakine in Pacifastacus leniusculus, 205 or coelomic cytolytic factor (CCF) in Eisenia foetida.206

Interleukins have been identified in several invertebrates, including the sea urchin,207 oysters 208,209 and snails163 and act as immune defense mediators. Interestingly, in the snail Biomphalaria glabrata interleukin treatment changes the cellular encapsulation process toward a humoral clearance mechanism, 210 this phenotypic shift being similar to the one observed in innate immune memory. 24

Granulins are evolutionarily conserved growth factors described from plants to vertebrates. In invertebrates (mollusk and insect), granulins drive proliferation or differentiation of immune cells and participate in the hemocyte activation of the anti-pathogen defense response.202,204

Macrophage Migration Inhibitory Factor (MIF) has been described in snail to activate hemocyte proliferation and differentiation.201 In Aphids, MIF cytokine was secreted with salivary compounds during feeding and was shown to repress plant immune response.203

In Drosophila melanogaster several signaling pathways, including the JAK/STAT, späzle and Toll pathways, are known to activate hemocytes. Following parasitoïd wasp infection hemocytes secreted Upd2 and Upd3, two important cytokines leading to JAK/STAT activation that is required for an efficient encapsulation of wasp eggs. Toll signaling initiates a systemic response in which hemocytes are mobilized and activated 211

Understanding how innate immune memory systemic acquisition is mediated in invertebrates and how memory is stored or recorded in hemocytes, hematopoietic organ or other progenitor cellsproducing tissues is an issue of future investigations.

\subsection{Offspring transfer of innate immune memory phenotype:}

An abiding question in biology is whether acquired characteristics can be inherited.212 One fascinating observation in invertebrate immune priming involves the transfer of an acquired protective effect from one parent to its offspring. This phenomenon is called trans-generational immune priming (TGIP). TGIP is considered a form of innate immune "memory." During the induction of this process, immune priming of the parental generation leads to stronger immune reactions or improved resistance of the offspring.

\subsection{1 | Trans-generational immune priming in plants}

Several recent studies reported on trans-generational defense priming and SAR in Arabidopsis and inherited anti-herbivore defense in tomato.213-215 One study showed that progeny of Pseudomonas-infected Arabidopsis plants was primed for enhanced activation of defense genes and for immunity to the infectious oomycete Hyaloperonospora arabidopsidis and to pathogenic Pseudomonads.213 Because transgenerational priming and SAR continued for more than one generation, the authors proposed an epigenetic basis of the phenomenon. Supporting this, $\mathrm{H} 3 \mathrm{~K} 9 \mathrm{ac}$, an epigenetic tag of a permissive state of transcription, was enhanced in the $5^{\prime}$ leader sequence of defense genes PR1, WRKY6, and WRKY53 in the offspring of Pseudomonasinfected Arabidopsis plants. Consistently, the trans-generational phenotype was not observed in the 
priming/SAR-deficient npr1 mutant.133,213,216 In addition, the Arabidopsis drm1drm2cmt3 triple mutant with reduced non-CpG DNA methylation mimicked the transgenerational priming/SAR phenotype.213 Furthermore, Pseudomonas infection caused DNA hypomethylation in Arabidopsis. 217 Therefore, it was proposed that next-generation priming and SAR were mediated by DNA hypo-methylation.213 However, the genome of many organisms with trans-generational memory (eg, Drosophila, Caenorhabditis elegans) does not encode DNA methyl-transferases.218 Therefore, DNA methylation cannot provide a universal epigenetic immune memory. It could be limited to plants.

Another study disclosed that progeny of BABA-treated or Pseudomonas-inoculated Arabidopsis mounted enhanced defense gene expression associated with immunity to Pseudomonas and $\mathrm{H}$. arabidopsidis. 215 It seems that even the capacity for expressing priming can be inherited because offspring of primed Arabidopsis plants show more robust priming than progeny of the un-primed control (so-called primed-for-priming phenotype). 215 Interestingly, it was reported recently that Arabidopsis and tomato plants are capable also of inheriting resistance to herbivory.214 The enhanced resistance to caterpillar feeding in the progeny of primed Arabidopsis plants was found to depend on functional DICER-like enzymes. This finding suggests involvement of small RNAs (sRNAs) in nextgenerational defense priming.

\subsection{2 | Trans-generational immune priming in invertebrates}

In invertebrates, TGIP specifically refers to the vertical transmission of the immunological experience from the parent(s) to the offspring.219,220 The first evidence of TGIP in invertebrates was described in 1999 for the crustacean Penaeusmonodon with mothers transfer offspring protection against the white spot syndrome virus (WSSV).219 Since then, TGIP has been demonstrated in numerous invertebrate species belonging mainly to arthropods.13,221

TGIP in insects was suspected to be associated with prophenoloxidase, antimicrobial peptides (AMP) and vitellogenin pathways. AMPs transfer and storage from mothers into the eggs have been demonstrated222-224 and recently AMPs were found over- expressed in bumblebee worker offspring hatched by queens injected with the bacteria Arthrobacter globiformis.225 Vitellogenin, the major egg storage resource for embryo nutrition, has been demonstrated to display multiple immune functions. Vitellogenin can act as a multivalent pattern recognition receptor (PRR) with an opsonin and antibacterial activity.226 Vitellogenin can recognize bacteria by specifically binding to pathogen-associated molecular patterns (PAMPs), such as PGN and LPS, and mediate the translocation of bacterial proteins to the eggs.227 This transfer was associated with an increased expression of immune genes in the eggs.227-229

In invertebrates, modifications of gene methylation and histone acetylation are the major epigenetic factors that could regulate immune response toward bacteria, viruses or fungi $845.170,230$ However solely two studies have investigated the role of epigenetics in TGIP, one on histone acetylation in the response of the crustacean Artemia sp. to Vibrio campbelli231 and the other on gene methylation after bacterial exposure of T. Castaneum.229 Unfortunately, none has succeeded to highlight a link between those epigenetic modifications and TGIP. The involvement of microRNA, IncRNA, and changes in chromatin structure has not been investigated in TGIP, despite their known role in invertebrate immunity and host-pathogens interaction.232,233 Interestingly a recent study has demonstrated in the greater wax moth Galleria mellonella that experimental resistance selection to Bacillus thuringiensis (Bt) results in the modification of acetylation of specific histones and DNA methylation as well as transcription of genes encoding the enzymatic writers and erasers of these epigenetic mechanisms in the offspring.234 
Thus, considering the prominent role of epigenetics in many transgenerational adaptation process in animals and its implication in the modulation of several immune response pathways, its involvement in TGIP must be now more deeply and widely investigated.169,235

\subsection{3 | Trans-generational immune priming in vertebrates}

Only very few, if any, data are available regarding transgenerational transmission of infection resistance in vertebrates. Trans-generational parental effect has been identified in vertebrates in which offspring enhanced immunity can be mediated by maternal antibodies, hormones and nutrients provided via placenta and milk in mammals and via the egg yolk in birds and reptiles.236 It has been also demonstrated that experience of stressful, toxic or polluted environment encountered by the parents can be transfer to the offspring by an epigenetic reprogramming of the fetus that can last for several generations. 237 Indeed, trans-generational transmission of epigenetic marks, including H3K9me and H3K27me induced by metabolic factors, toxins, or stress has been reported.238-240 But no studies have investigated the transmission of resistance to infections between generations. However, a very recent study reported that BCG vaccination of the mother improves the response of the child to BCG,241 an indirect argument for trans-generational transmission of resistance traits. These observations may suggest that trained immunity is also transmitted trans-generationally in vertebrates, and more studies are warranted to investigate it. The trans-generational transmission of epigenetic traits is under much debated in vertebrates, and it remains to be demonstrated in the case of innate immune memory.

\section{I POST-LAMARCKISM/NEO-DARWINISM SELECTION}

Acquisition of innate immune memory can be interpreted as a within-generation resistance mechanism described by Lamarck as non-Darwinian resistance process. Innate immune memory even has trans-generational Lamarckian characteristics, Lamarckian property may have important advantages during severe pandemic events when Darwinian evolution based on genetic variation and selection may be too slow to achieve survival of the species (Figures 3 and 4).

Following a primary infection or vaccination, a thymectomized mouse, an invertebrate animal, or a plant, can built innate immune memory. This innate immune memory represents an important mechanism through which resistance to disease can hi can be mediated by epigenetic reprogramming of innate immune cells. Moreover, the acquisition of homologous or heterologous rapid resistance to infections by innate immune memory process can select for the transmission in the progeny of increased patterns of transcription of host defense genes through a TGIP mechanism (Figure 4). The patterns to be transmitted trans-generationally are then chosen through the selective filter caused by the initial infection and may spread rapidly in the next generation.

Future studies will likely identify the precise mechanisms mediating these trans- generational effects. The process of the transgenerational epigenetic reprogramming likely mediated by soluble regulators such as cytokines, growth factors or non-coding RNAs (miRNA or IncRNA) remains to be demonstrated. These regulators need to target not solely to somatic but also to germinal cells to induce specific epigenetic regulations that may lead to changes in immune function that can be transmitted to the next generation, and subsequently confer an increased resistance to infections. If that occurs in the $n+1$ generation the individuals and more precisely their immune system may well possess both, an acquired resistance from the trans-generational trained immunity, but can also be trained once more through epigenetic reprogramming following an 
encounter with new pathogens (Figure 4). This resistance phenotype that is inherited is reminiscent of the acquired phenotype proposed by Lamarck (1744-1829). This de facto infection- induced, epigenetically mediated Lamarckian evolution will complement the much better known selection of the resistant individuals through the natural selection process described by Darwin (1809-1882). Both processes, which reconcile Lamarckian and Darwinian evolutionary selection, may diversify the sources of selective value and can be intimately associated in the evolution of eukaryotes.

\section{I CONCLUDING REMARKS AND FUTURE CHALLENGES OF RESE ARCH IN THE FIELD OF INNATE IMMUNE MEMORY}

There is increasing body of evidence for innate immune responses exhibiting adaptive characteristics.15,25 In plants and invertebrates, despite the absence of adaptive immune cells and the lack of clonal selection, adaptation within the innate immune response has been described, leading to innate immune memory and resistance against re-infection.12,26 In addition previous and recent studies in mammals have demonstrated that certain mild infections or vaccination with attenuated microorganisms lead to the induction of crossprotection against infections with different pathogens.174 It is thus apparent that innate immunity can be modulated by previous encounters with pathogens or their products. Several terminologies have been proposed to describe innate immune memory, depending of the type of infection and model host studied: in plants, the term defense priming describes the immune memory in SAR, ISR, and BABA-IR, the immune priming in invertebrates, or the trained immunity in the vertebrates. Compared to adaptive immunity, trained immunity is exerted by innate immune cells (eg, monocyte or NK in vertebrates, hemocytes in invertebrates), which are no specific and have a short-lived response, or by every single cell in plants. Innate immune memory can be mediated partially through epigenetic modifications induced by signal transduction impinging on transcription factors. Such epigenetic reprogramming does not involve permanent genetic changes such as mutations and recombination; by changing the accessibility of chromatin for transcription, gene expression is changed with consequences for cell functions and acquisition of new immune capabilities that can be related to a Neo-Lamarckian inheritance system. The similarity of these processes from prokaryotes to vertebrates (Figure 2) argues for the possibility that innate immune memory is an ancestral biological process that evolved for protection of multicellular organisms lacking adaptive immune responses.

The arguments presented above suggest that innate immune memory is a fundamental characteristic of host defense. Much remains to be learned in this field that gather together immunology across living kingdoms in the upcoming years. The field of innate immunological memory is very active, and it is on the brink of new discoveries: this progress will come from both the proposal of novel concepts, as well as from a revolution in the tools available. We have just started to understand the impact of tissue environment on the induction of immune memory, and we expect this to be a very fruitful area of research. Similarly, induction of innate immune memory at tissue level, rather than only in the bone marrow and circulation, will likely revolutionize our understanding of local immune responses. A very recent study demonstrating epigenetically mediated inflammation-induced memory in skin cell progenitors is just a first step in that direction. 242 Our understanding of the impact of external factors, such as the host microbiome, on immune memory is currently in its infancy, but we believe that crucial discoveries will emerge from this area in the years to come. These discoveries will be enabled by the availability of large cohorts of individuals whose detailed immunological phenotyping has been performed, and the use of a system biology approach and cutting-edge 'omics' technologies will also contribute greatly. A key question to answer in the future concerns our understanding of the induction of 
immune memory at the single cell level, and identifying the cell subpopulations which should initiate the immune memory phenotype. Finally, a key goal for the infant field of innate immune memory is to identify the detailed mechanisms mediating these processes and the overall impact of innate memory in physiology and disease. Only when these aims will be achieved we will have a comprehensive view of the impact of innate immune memory on resistance to infections and its implications for human diseases, leading to both a better biological understanding of host defense and the identification of novel approaches for diagnosis and therapy in human diseases or plant and animal pathologies.

\section{ACKNOWLEDGEMENTS}

BG was supported by ANR JCJC INVIMORY (number ANR 13-JSV7- 0009) from the French National Research Agency (ANR). Work on defence priming in the Conrath lab is supported by German Research Foundation (grant CO 186/13-1), the Excellence Initiative of the German federal and state governments, and Bayer CropScience. MGN was supported by an ERC Consolidator Grant (\#310372) and a Spinoza Grant of the Netherlands Organization for Scientific Research.

\section{CONFLICTS OF INTEREST}

Authors do not have any conflicts of interest to declare. 


\section{REFERENCES}

1. Howard JC. Immunology. Disease and evolution. Nature. 1991;352:565-567.

2. Combes C. Selective pressure in host-parasite systems. J Soc Biol. 2000;194:19-23.

3. Howard JC, Jack RS. Evolution of immunity and pathogens. Eur J Immunol. 2007;37:1721-1723.

4. Akira S, Uematsu S, Takeuchi O. Pathogen recognition and innate immunity. Cell. 2006;124:783-801.

5. Barrangou R, Marraffini LA. CRISPR-Cas systems: Prokaryotes upgrade to adaptive immunity. Mol Cell. 2014;54:234-244.

6. Purvis A, Hector A. Getting the measure of biodiversity. Nature. 2000;405:212-219.

7. Kishishita N, Nagawa F. Evolution of adaptive immunity: Implications of a third lymphocyte lineage in lampreys. BioEssays. 2014;36:244-250.

8. Buchmann K. Evolution of innate immunity: Clues from invertebrates via fish to mammals. Front Immunol. 2014;5:459.

9. Cooper MD, Alder MN. The evolution of adaptive immune systems. Cell. 2006;124:815-822.

10. Greischar MA, Koskella B. A synthesis of experimental work on parasite local adaptation. Ecol Lett. 2007;10:418-434.

11. Penczykowski RM, Laine AL, Koskella B. Understanding the ecology and evolution of host-parasite interactions across scales. Evol Appl. 2015;9:37-52.

12. Conrath U, Beckers GJ, Langenbach CJ, Jaskiewicz MR. Priming for enhanced defense. Annu Rev Phytopathol. 2015;53:97-119.

13. Milutinovic B, Kurtz J. Immune memory in invertebrates. Semin Immunol. 2016;28:328-342.

14. Reimer-Michalski EM, Conrath U. Innate immune memory in plants. Semin Immunol. 2016;28:319327.

15. Netea MG, Quintin J, van der Meer JW. Trained immunity: A memory for innate host defense. Cell Host Microbe. 2011;9:355-361.

16. Sun JC, Ugolini S, Vivier E. Immunological memory within the innate immune system. EMBO J. 2014;33:1295-1303.

17. Coustau C, Kurtz J, Moret Y. A novel mechanism of immune memory unveiled at the invertebrateparasite interface. Trends Parasitol. 2016;32:353-355.

18. Cooper D, Eleftherianos I. Memory and specificity in the insect immune system: Current perspectives and future challenges. Front Immunol. 2017;8:539.

19. Kurtz J. Memory in the innate and adaptive immune systems. Microbes Infect. 2004;6:1410-1417.

20. Portela J, Duval D, Rognon A, et al. Evidence for specific genotypedependent immune priming in the lophotrochozoan Biomphalaria glabrata Snail. J Innate Immun. 2013;5:261-276.

21. Rodrigues J, Brayner FA, Alves LC, Dixit R, Barillas-Mury C. Hemocyte differentiation mediates innate immune memory in Anopheles gambiae mosquitoes. Science. 2010;329:1353-1355.

22. Sadd BM, Schmid-Hempel P. Insect immunity shows specificity in protection upon secondary pathogen exposure. Curr Biol. 2006;16:1206-1210.

23. Kurtz J, Franz K. Innate defence: Evidence for memory in invertebrate immunity. Nature. 2003;425:37-38.

24. Pinaud S, Portela J, Duval D, et al. A shift from cellular to humoral responses contributes to innate immune memory in the vector snail Biomphalaria glabrata. PLoS Pathog. 2016;12:e1005361.

25. Bowdish DM, Loffredo MS, Mukhopadhyay S, Mantovani A, Gordon S. Macrophage receptors implicated in the "adaptive" form of innate immunity. Microbes Infect. 2007;9:1680-1687.

26. Kurtz J. Specific memory within innate immune systems. Trends Immunol. 2005;26:186-192.

27. Pieterse CM, Zamioudis C, Berendsen RL, Weller DM, Van Wees SC, Bakker PA. Induced systemic resistance by beneficial microbes. Annu Rev Phytopathol. 2014;52:347-375.

28. Conrath U, Pieterse CM, Mauch-Mani B. Priming in plant-pathogen interactions. Trends Plant Sci. 2002;7:210-216. 
29. Fu ZQ, Dong X. Systemic acquired resistance: Turning local infection into global defense. Annu Rev Plant Biol. 2013;64:839-863.

30. Jakab G, Cottier V, Toquin V, et al. $\beta$-Aminobutyric acid-induced resistance in plants. Plant Physiol. 2001;107:29.

31. Quintin J, Saeed S, Martens JHA, et al. Candida albicans infection affords protection against reinfection via functional reprogramming of monocytes. Cell Host Microbe. 2012;12:223-232.

32. Ifrim DC, Quintin J, Joosten LA, et al. Trained immunity or tolerance: Opposing functional programs induced in human monocytes after engagement of various pattern recognition receptors. Clin Vaccine Immunol. 2014;21:534-545.

33. Di Noia JM, Neuberger MS. Molecular mechanisms of antibody somatic hypermutation. Annu Rev Biochem. 2007;76:1-22.

34. Reynaud CA, Bertocci B, Dahan A, Weill JC. Formation of the chicken B-cell repertoire: Ontogenesis, regulation of Ig gene rearrangement, and diversification by gene conversion. Adv Immunol. 1994;57:353-378.

35. Tonegawa S. Somatic generation of antibody diversity. Nature. 1983;302:575-581.

36. Du Pasquier L. The immune system of invertebrates and vertebrates. Comp Biochem Physiol B Biochem Mol Biol. 2001;129:1-15.

37. Cannon JP, Haire RN, Schnitker N, Mueller MG, Litman GW. Individual protochordates have unique immune-type receptor repertoires. Curr Biol. 2004;14:R465-R466.

38. Pancer Z, Amemiya CT, Ehrhardt GR, Ceitlin J, Gartland GL, Cooper MD. Somatic diversification of variable lymphocyte receptors in the agnathan sea lamprey. Nature. 2004;430:174-180.

39. Flajnik MF, Kasahara M. Comparative genomics of the MHC: Glimpses into the evolution of the adaptive immune system. Immunity. 2001;15:351-362.

40. Medzhitov R, Janeway CA Jr. Innate immunity: The virtues of a nonclonal system of recognition. Cell. 1997;91:295-298.

41. Pancer Z. Dynamic expression of multiple scavenger receptor cysteine-rich genes in coelomocytes of the purple sea urchin. Proc Natl Acad Sci USA. 2000;97:13156-13161.

42. Dong Y, Taylor HE, Dimopoulos G. AgDscam, a hypervariable immunoglobulin domain-containing receptor of the Anopheles gambiae innate immune system. PLoS Biol. 2006;4:e229.

43. Watson FL, Puttmann-Holgado R, Thomas F, et al. Extensive diversity of Ig-superfamily proteins in the immune system of insects. Science. 2005;309:1874-1878.

44. Brites D, McTaggart S, Morris K, et al. The Dscam homologue of the crustacean Daphnia is diversified by alternative splicing like in insects. Mol Biol Evol. 2008;25:1429-1439.

45. Zhang SM, Adema CM, Kepler TB, Loker ES. Diversification of Ig superfamily genes in an invertebrate. Science. 2004;305: 251-254.

46. Sandiford SL, Dong Y, Pike A, Blumberg BJ, Bahia AC, Dimopoulos G. Cytoplasmic actin is an extracellular insect immune factor which is secreted upon immune challenge and mediates phagocytosis and direct killing of bacteria, and is a Plasmodium Antagonist. PLoS Pathog. 2015;11:e1004631.

47. Tetreau G, Pinaud S, Portet A, Galinier R, Gourbal B, Duval D. Specific pathogen recognition by multiple innate immune sensors in an invertebrate. Front Immunol. 2017;8:1249.

48. Hargreaves DC, Medzhitov R. Innate sensors of microbial infection. J Clin Immunol. 2005;25:503510.

49. Coffaro KA, Hinegardner RT. Immune response in the sea urchin Lytechinus pictus. Science. 1977;197:1389-1390.

50. Cooper EL. Transplantation immunity in annelids. I. Rejection of xenografts exchanged between Lumbricus terrestris and Eisenia foetida. Transplantation. 1968;6:322-327. 
51. Hildemann WH, Johnson IS, Jokiel PL. Immunocompetence in the lowest metazoan phylum: Transplantation immunity in sponges. Science. 1979;204:420-422.

52. Hildemann WH, Raison RL, Cheung G, Hull CJ, Akaka L, Okamoto J. Immunological specificity and memory in a scleractinian coral. Nature. 1977;270:219-223.

53. Cooper EL, Rinkevich B, Uhlenbruck G, Valembois P. Invertebrate immunity: Another viewpoint. Scand J Immunol. 1992;35:247-266.

54. Felix G, Duran JD, Volko S, Boller T. Plants have a sensitive perception system for the most conserved domain of bacterial flagellin. Plant J. 1999;18:265-276.

55. Nurnberger T, Kemmerling B. Receptor protein kinases-pattern recognition receptors in plant immunity. Trends Plant Sci. 2006;11:519-522.

56. Zipfel C. Plant pattern-recognition receptors. Trends Immunol. 2014;35:345-351.

57. Couto D, Zipfel C. Regulation of pattern recognition receptor signalling in plants. Nat Rev Immunol. 2016;16:537-552.

58. Uma B, Rani TS, Podile AR. Warriors at the gate that never sleep: Non-host resistance in plants. J Plant Physiol. 2011;168:2141-2152.

59. Flor H. Inheritance of pathogenicity in Melampsoralini. Phytopathology. 1942;32:653-669.

60. Flor H. Current status of the gene-for-gene concept. Annu Rev Phytopathol. 1971;9:323-329.

61. Dodds PN, Rathjen JP. Plant immunity: Towards an integrated view of plant- pathogen interactions. Nat Rev Genet. 2010;11:539-548.

62. Jones JD, Dangl JL. The plant immune system. Nature. 2006;444:323-329.

63. Khan M, Subramaniam R, Desveaux D. Of guards, decoys, baits and traps: Pathogen perception in plants by type III effector sensors. Curr Opin Microbiol. 2015;29:49-55.

64. Mackey D, Belkhadir Y, Alonso JM, Ecker JR, Dangl JL. Arabidopsis RIN4 is a target of the type III virulence effector AvrRpt2 and modulates RPS2-mediated resistance. Cell. 2003;112:379-389.

65. Coll NS, Epple P, Dangl JL. Programmed cell death in the plant immune system. Cell Death Differ. 2011;18:1247-1256.

66. Heidrich K, Wirthmueller L, Tasset C, Pouzet C, Deslandes L, Parker JE. Arabidopsis EDS1 connects pathogen effector recognition to cell compartment-specific immune responses. Science. 2011;334:1401-1404.

67. Levine A, Tenhaken R, Dixon R, Lamb C. $\mathrm{H} 2 \mathrm{O} 2$ from the oxidative burst orchestrates the plant hypersensitive disease resistance response. Cell. 1994;79:583-593.

68. Navarro L, Zipfel C, Rowland O, et al. The transcriptional innate immune response to flg22. Interplay and overlap with Avr genedependent defense responses and bacterial pathogenesis. Plant Physiol. 2004;135:1113-1128.

69. Tsuda K, Katagiri F. Comparing signaling mechanisms engaged in pattern-triggered and effectortriggered immunity. Curr Opin Plant Biol. 2010;13:459-465.

70. Tsuda K, Somssich IE. Transcriptional networks in plant immunity. New Phytol. 2015;206:932-947.

71. Tao Y, Xie Z, Chen W, et al. Quantitative nature of Arabidopsis responses during compatible and incompatible interactions with the bacterial pathogen Pseudomonas syringae. Plant Cell. 2003;15:317-330.

72. Zipfel C, Kunze G, Chinchilla D, et al. Perception of the bacterial PAMP EF-Tu by the receptor EFR restricts Agrobacteriummediated transformation. Cell. 2006;125:749-760.

73. Caldo RA, Nettleton D, Wise RP. Interaction-dependent gene expression in Mla- specified response to barley powdery mildew. Plant Cell. 2004;16:2514-2528.

74. Ausubel FM. Are innate immune signaling pathways in plants and animals conserved? Nat Immunol. 2005;6:973-979.

75. Diacovich L, Gorvel JP. Bacterial manipulation of innate immunity to promote infection. Nat Rev Microbiol. 2010;8:117-128. 
76. Gomez-Gomez L, Felix G, Boller T. A single locus determines sensitivity to bacterial flagellin in Arabidopsis thaliana. Plant J. 1999;18:277-284.

77. Hayashi F, Smith KD, Ozinsky A, et al. The innate immune response to bacterial flagellin is mediated by Toll-like receptor 5. Nature. 2001;410:1099-1103.

78. Kumar S, Ingle H, Prasad DV, Kumar H. Recognition of bacterial infection by innate immune sensors. Crit Rev Microbiol. 2013;39:229-246.

79. Stuart LM, Paquette N, Boyer L. Effector-triggered versus patterntriggered immunity: How animals sense pathogens. Nat Rev Immunol. 2013;13:199-206.

80. Netea MG, Joosten LA, Latz E, et al. Trained immunity: A program of innate immune memory in health and disease. Science. 2016;352:aaf1098.

81. Saeed S, Quintin J, Kerstens HH, et al. Epigenetic programming of monocyte-to- macrophage differentiation and trained innate immunity. Science. 2014;345:1251086.

82. Benn CS, Netea MG, Selin LK, Aaby P. A small jab - a big effect: Nonspecific immunomodulation by vaccines. Trends Immunol. 2013;34:431-439.

83. Hendricks DW, Balfour HH Jr, Dunmire SK, Schmeling DO, Hogquist KA, Lanier LL. Cutting edge: NKG2C(hi)CD57 + NK cells respond specifically to acute infection with cytomegalovirus and not Epstein-Barr virus. J Immunol. 2014;192:4492-4496.

84. Min-Oo G, Lanier LL. Cytomegalovirus generates long-lived antigen-specific NK cells with diminished bystander activation to heterologous infection. J Exp Med. 2014;211:2669-2680.

85. Paust S, Gill HS, Wang BZ, et al. Critical role for the chemokine receptor CXCR6 in NK cell-mediated antigen-specific memory of haptens and viruses. Nat Immunol. 2010;11:1127-1135.

86. Sun JC, Beilke JN, Lanier LL. Adaptive immune features of natural killer cells. Nature. 2009;457:557561.

87. Desjardins M, Houde M, Gagnon E. Phagocytosis: The convoluted way from nutrition to adaptive immunity. Immunol Rev. 2005;207:158-165.

88. Hartenstein V. Blood cells and blood cell development in the animal kingdom. Annu Rev Cell Dev Biol. 2006;22:677-712.

89. Cooper EL. Evolution of immune systems from self/not self to danger to artificial immune systems (AIS). Phys Life Rev. 2010;7:55-78.

90. Zanchi C, Troussard JP, Martinaud G, Moreau J, Moret Y. Differential expression and costs between maternally and paternally derived immune priming for offspring in an insect. J Anim Ecol. 2011;80:1174-1183.

91. Dubuffet A, Zanchi C, Boutet G, Moreau J, Teixeira M, Moret Y. Trans-generational immune priming protects the eggs only against gram-positive bacteria in the mealworm beetle. PLoS Pathog. 2015;11:e1005178.

92. Hoffmann JA, Reichhart JM. Drosophila innate immunity: An evolutionary perspective. Nat Immunol. 2002;3:121-126.

93. Contreras-Garduno J, Rodriguez MC, Rodriguez MH, AlvaradoDelgado A, Lanz- MH. Cost of immune priming within generations: Trade-off between infection and reproduction. Microbes Infect. 2014;16:261-267.

94. Schmid-Hempel P. Immune defence, parasite evasion strategies and their relevance for 'macroscopic phenomena' such as virulence. Philos Trans R Soc Lond. 2009;364:85-98.

95. Koonin EV, Makarova KS. CRISPR-Cas: Evolution of an RNAbased adaptive immunity system in prokaryotes. RNA Biol. 2013;10:679-686.

96. Koonin EV, Makarova KS, Wolf YI. Evolutionary genomics of defense systems in archaea and bacteria. Annu Rev Microbiol. 2017;71:233-261.

97. Marraffini LA. CRISPR-Cas immunity in prokaryotes. Nature. 2015;526:55-61. 
98. Marakalala MJ, Williams DL, Hoving JC, Engstad R, Netea MG, Brown GD. Dectin- 1 plays a redundant role in the immunomodulatory activities of beta-glucan-rich ligands in vivo. Microbes Infect. 2013;15:511-515.

99. Krahenbuhl JL, Sharma SD, Ferraresi RW, Remington JS. Effects of muramyl dipeptide treatment on resistance to infection with Toxoplasma gondii in mice. Infect Immun. 1981;31:716-722.

100. Ribes $\mathrm{S}$, Meister $\mathrm{T}$, Ott $\mathrm{M}$, et al. Intraperitoneal prophylaxis with $\mathrm{CpG}$ oligodeoxynucleotides protects neutropenic mice against intracerebral Escherichia coli K1 infection. J Neuroinflammation. 2014;11:14.

101. Munoz N, Van Maele L, Marques JM, Rial A, Sirard JC, Chabalgoity JA. Mucosal administration of flagellin protects mice from Streptococcus pneumoniae lung infection. Infect Immun. 2010;78:4226-4233.

102. Zhang B, Chassaing B, Shi Z, et al. Viral infection. Prevention and cure of rotavirus infection via TLR5/NLRC4-mediated production of IL-22 and IL-18. Science. 2014;346:861-865.

103. van der Meer JW, Barza M, Wolff SM, Dinarello CA. A low dose of recombinant interleukin 1 protects granulocytopenic mice from lethal gram-negative infection. Proc Natl Acad Sci USA. 1988;85:1620-1623.

104. Ghisletti S, Barozzi I, Mietton F, et al. Identification and characterization of enhancers controlling the inflammatory gene expression program in macrophages. Immunity. 2010;32:317-328.

105. Foster SL, Hargreaves DC, Medzhitov R. Gene-specific control of inflammation by TLR-induced chromatin modifications. Nature. 2007;447:972-978.

106. Nicodeme E, Jeffrey KL, Schaefer U, et al. Suppression of inflammation by a synthetic histone mimic. Nature. 2010;468:1119-1123.

107. Kaikkonen MU, Spann NJ, Heinz S, et al. Remodeling of the enhancer landscape during macrophage activation is coupled to enhancer transcription. Mol Cell. 2013;51:310-325.

108. Ostuni R, Piccolo V, Barozzi I, et al. Latent enhancers activated by stimulation in differentiated cells. Cell. 2013;152:157-171.

109. Yoshida K, Maekawa T, Zhu Y, et al. The transcription factor ATF7 mediates lipopolysaccharideinduced epigenetic changes in macrophages involved in innate immunological memory. Nat Immunol. 2015;16:1034-1043.

110. Verma D, Parasa VR, Raffetseder J, et al. Anti-mycobacterial activity correlates with altered DNA methylation pattern in immune cells from BCG-vaccinated subjects. Sci Rep. 2017;7:12305.

111. Tribouley J, Tribouley-Duret J, Appriou M. [Effect of Bacillus Callmette Guerin (BCG) on the receptivity of nude mice to Schistosoma mansoni]. C R Seances Soc Biol Fil. 1978;172:902-904.

112. van 't Wout JW, Poell $R$, van Furth $R$. The role of BCG/PPDactivated macrophages in resistance against systemic candidiasis in mice. Scand J Immunol. 1992;36:713-719.

113. Bistoni F, Vecchiarelli A, Cenci E, Puccetti P, Marconi P, Cassone A. Evidence for macrophagemediated protection against lethal Candida albicans infection. Infect Immun. 1986;51:668-674.

114. Bistoni F, Verducci G, Perito S, et al. Immunomodulation by a low-virulence, agerminative variant of Candida albicans. Further evidence for macrophage activation as one of the effector mechanisms of nonspecific anti-infectious protection. J Med Vet Mycol. 1988;26:285-299.

115. Vecchiarelli A, Cenci E, Marconi P, Rossi R, Riccardi C, Bistoni F. Immunosuppressive effect of cyclosporin $A$ on resistance to systemic infection with Candida albicans. J Med Microbiol. 1989;30:183-192.

116. Barton ES, White DW, Cathelyn JS, et al. Herpesvirus latency confers symbiotic protection from bacterial infection. Nature. 2007;447:326-329.

117. Chen F, Wu W, Millman A, et al. Neutrophils prime a long-lived effector macrophage phenotype that mediates accelerated helminth expulsion. Nat Immunol. 2014;15:938-946. 
118. Nabekura T, Girard JP, Lanier LL. IL-33 receptor ST2 amplifies the expansion of NK cells and enhances host defense during mouse cytomegalovirus infection. J Immunol. 2015;194:59485952.

119. Schlums H, Cichocki F, Tesi B, et al. Cytomegalovirus infection drives adaptive epigenetic diversification of NK cells with altered signaling and effector function. Immunity. 2015;42:443456.

120. Sun JC, Madera S, Bezman NA, Beilke JN, Kaplan MH, Lanier LL. Proinflammatory cytokine signaling required for the generation of natural killer cell memory. J Exp Med. 2012;209:947-954.

121. Askenase MH, Han SJ, Byrd AL, et al. Bone-marrow-resident NK cells prime monocytes for regulatory function during infection. Immunity. 2015;42:1130-1142.

122. Nabekura T, Kanaya M, Shibuya A, Fu G, Gascoigne NR, Lanier LL. Costimulatory molecule DNAM1 is essential for optimal differentiation of memory natural killer cells during mouse cytomegalovirus infection. Immunity. 2014;40:225-234.

123. Beckers GJ, Jaskiewicz M, Liu Y, et al. Mitogen-activated protein kinases 3 and 6 are required for full priming of stress responses in Arabidopsis thaliana. Plant Cell. 2009;21:944-953.

124. Ryals JA, Neuenschwander UH, Willits MG, Molina A, Steiner HY, Hunt MD. Systemic acquired resistance. Plant Cell. 1996;8:1809-1819.

125. Tateda C, Zhang Z, Shrestha J, Jelenska J, Chinchilla D, Greenberg JT. Salicylic acid regulates Arabidopsis microbial pattern receptor kinase levels and signaling. Plant Cell. 2014;26:41714187.

126. Robatzek S, Wirthmueller L. Mapping FLS2 function to structure: LRRs, kinase and its working bits. Protoplasma. 2013;250: 671-681.

127. Navarova H, Bernsdorff F, Doring AC, Zeier J. Pipecolic acid, an endogenous mediator of defense amplification and priming, is a critical regulator of inducible plant immunity. Plant Cell. 2012;24:5123-5141.

128. Asai T, Tena G, Plotnikova J, et al. MAP kinase signalling cascade in Arabidopsis innate immunity. Nature. 2002;415:977-983.

129. Lee J, Eschen-Lippold L, Lassowskat I, Bottcher C, Scheel D. Cellular reprogramming through mitogen-activated protein kinases. Front Plant Sci. 2015;6:940.

130. Meng X, Zhang S. MAPK cascades in plant disease resistance signaling. Annu Rev Phytopathol. 2013;51:245-266.

131. Nakagami H, Pitzschke A, Hirt H. Emerging MAP kinase pathways in plant stress signalling. Trends Plant Sci. 2005;10:339-346.

132. Yi SY, Min SR, Kwon SY. NPR1 is instrumental in priming for the enhanced flg22-induced MPK3 and MPK6 activation. Plant Pathol J. 2015;31:192-194.

133. Cao H, Bowling SA, Gordon AS, Dong X. Characterization of an Arabidopsis mutant that is nonresponsive to inducers of systemic acquired resistance. Plant Cell. 1994;6:1583-1592.

134. Dong X. NPR1, all things considered. Curr Opin Plant Biol. 2004;7:547-552.

135. Mou Z, Fan W, Dong X. Inducers of plant systemic acquired resistance regulate NPR1 function through redox changes. Cell. 2003;113:935-944.

136. Gentry M, Hennig L. Remodelling chromatin to shape development of plants. Exp Cell Res. 2014;321:40-46.

137. Henikoff S, Shilatifard A. Histone modification: Cause or cog? Trends Genet. 2011;27:389-396.

138. Peterson CL, Laniel MA. Histones and histone modifications. Curr Biol. 2004;14:R546-551.

139. Berr A, Shafiq $S$, Shen WH. Histone modifications in transcriptional activation during plant development. Biochim Biophys Acta. 2011;1809:567-576.

140. Badeaux Al, Shi Y. Emerging roles for chromatin as a signal integration and storage platform. Nat Rev. 2013;14:211-224. 
141. Berr A, Menard R, Heitz T, Shen WH. Chromatin modification and remodelling: A regulatory landscape for the control of Arabidopsis defence responses upon pathogen attack. Cell Microbiol. 2012;14:829-839.

142. Bird A. DNA methylation patterns and epigenetic memory. Genes Dev. 2002;16:6-21.

143. Kim MY, Zilberman D. DNA methylation as a system of plant genomic immunity. Trends Plant Sci. 2014;19:320-326.

144. Roudier F, Ahmed I, Berard C, et al. Integrative epigenomic mapping defines four main chromatin states in Arabidopsis. EMBO J. 2011;30:1928-1938.

145. Roudier F, Teixeira FK, Colot V. Chromatin indexing in Arabidopsis: An epigenomic tale of tails and more. Trends Genet. 2009;25:511-517.

146. Schwammle V, Aspalter CM, Sidoli S, Jensen ON. Large scale analysis of co- existing posttranslational modifications in histone tails reveals global fine structure of cross-talk. Mol Cell Proteomics. 2014;13:1855-1865.

147. Eberharter A, Becker PB. Histone acetylation: A switch between repressive and permissive chromatin. Second in review series on chromatin dynamics. EMBO Rep. 2002;3:224-229.

148. Kanno T, Kanno Y, Siegel RM, Jang MK, Lenardo MJ, Ozato K. Selective recognition of acetylated histones by bromodomain proteins visualized in living cells. Mol Cell. 2004;13:33-43.

149. Ng MK, Cheung P. A brief histone in time: Understanding the combinatorial functions of histone PTMs in the nucleosome context. Biochem Cell Biol. 2015;94:33-42.

150. Zhang X. The epigenetic landscape of plants. Science. 2008;320:489-492.

151. Zhang Y, Reinberg D. Transcription regulation by histone methylation: Interplay between different covalent modifications of the core histone tails. Genes Dev. 2001;15:2343-2360.

152. He G, Elling AA, Deng XW. The epigenome and plant development. Annu Rev Plant Biol. 2011;62:411-435.

153. Alvarez-Venegas R, Abdallat AA, Guo M, Alfano JR, Avramova Z. Epigenetic control of a transcription factor at the cross section of two antagonistic pathways. Epigenetics. 2007;2:106113.

154. Jaskiewicz M, Conrath U, Peterhansel C. Chromatin modification acts as a memory for systemic acquired resistance in the plant stress response. EMBO Rep. 2011;12:50-55.

155. Pokholok DK, Harbison CT, Levine S, et al. Genome-wide map of nucleosome acetylation and methylation in yeast. Cell. 2005;122:517-527.

156. de la Cruz X, Lois S, Sanchez-Molina S, Martinez-Balbas MA. Do protein motifs read the histone code? BioEssays. 2005;27:164-175.

157. Feng S, Jacobsen SE, Reik W. Epigenetic reprogramming in plant and animal development. Science. 2010;330:622-627.

158. Vermeulen M, Mulder KW, Denissov S, et al. Selective anchoring of TFIID to nucleosomes by trimethylation of histone H3 lysine 4. Cell. 2007;131:58-69.

159. Greenwood JM, Milutinovic B, Peuss R, et al. Oral immune priming with Bacillus thuringiensis induces a shift in the gene expression of Tribolium castaneum larvae. BMC Genom. 2017;18:329.

160. Pham LN, Dionne MS, Shirasu-Hiza M, Schneider DS. A specific primed immune response in Drosophila is dependent on phagocytes. PLoS Pathog. 2007;3:e26.

161. Wu G, Li M, Liu Y, Ding Y, Yi Y. The specificity of immune priming in silkworm, Bombyx mori, is mediated by the phagocytic ability of granular cells. J Insect Physiol. 2015;81:60-68.

162. Honti V, Csordas G, Kurucz E, Markus R, Ando I. The cell-mediated immunity of Drosophila melanogaster: Hemocyte lineages, immune compartments, microanatomy and regulation. Dev Comp Immunol. 2013;42:47-56.

163. Adema CM, Hillier LW, Jones CS, et al. Whole genome analysis of a schistosomiasis-transmitting freshwater snail. Nat Commun. 2017;8:15451. 
164. Jenkins AM, Muskavitch MA. Evolution of an epigenetic gene ensemble within the genus Anopheles. Genome Biol Evol. 2015;7:901-915.

165. Dennison NJ, BenMarzouk-Hidalgo OJ, Dimopoulos G. MicroRNAregulation of Anopheles gambiae immunity to Plasmodium falciparum infection and midgut microbiota. Dev Comp Immunol. 2015;49:170-178.

166. Lampe L, Levashina EA. The role of microRNAs in Anopheles biology-an emerging research field. Parasite Immunol. 2017;39:1-10.

167. Huang $Q$, Chen Y, Wang RW, Schwarz RS, Evans JD. Honey bee microRNAs respond to infection by the microsporidian parasite Nosema ceranae. Sci Rep. 2015;5:17494.

168. Monsanto-Hearne V, Tham AL, Wong ZS, Asgari S, Johnson KN. Drosophila miR- 956 suppression modulates Ectoderm-expressed 4 and inhibits viral replication. Virology. 2017;502:20-27.

169. Vilcinskas $A$. The role of epigenetics in host-parasite coevolution: Lessons from the model host insects Galleria mellonella and Tribolium castaneum. Zoology (Jena, Germany). 2016;119:273280.

170. Galbraith DA, Yang X, Nino EL, Yi S, Grozinger C. Parallel epigenomic and transcriptomic responses to viral infection in honey bees (Apis mellifera). PLoS Pathog. 2015;11:e1004713.

171. Geyer KK, Niazi UH, Duval D, et al. The Biomphalaria glabrata DNA methylation machinery displays spatial tissue expression, is differentially active in distinct snail populations and is modulated by interactions with Schistosoma mansoni. PLoS Negl Trop Dis. 2017;11:e0005246.

172. Gomez-Diaz E, Rivero A, Chandre F, Corces VG. Insights into the epigenomic landscape of the human malaria vector Anopheles gambiae. Front Genet. 2014;5:277.

173. Heitmueller M, Billion A, Dobrindt U, Vilcinskas A, Mukherjee K. Epigenetic mechanisms regulate innate immunity against uropathogenic and commensal-like Escherichia coli in the surrogate insect model Galleria mellonella. Infect Immun. 2017;85:e00336-17.

174. Quintin J, Cheng SC, van der Meer JW, Netea MG. Innate immune memory: Towards a better understanding of host defense mechanisms. Curr Opin Immunol. 2014;29:1-7.

175. Cerenius L, Soderhall K. Variable immune molecules in invertebrates. J Exp Biol. 2013;216:43134319.

176. Coustau C, Gourbal B, Duval D, Yoshino TP, Adema CM, Mitta G. Advances in gastropod immunity from the study of the interaction between the snail Biomphalaria glabrata and its parasites: A review of research progress over the last decade. Fish Shellfish Immunol. 2015;46:5-16.

177. Escoubas J-M, Destoumieus-Garzon D, Montagnani C, etal. Immunity in Molluscs. In: Ratcliffe MJH, ed. Encyclopedia of Immunology, Vol. 1. Oxford, UK: Oxford Academic Press; 2015:417436.

178. Yona S, Kim KW, Wolf Y, et al. Fate mapping reveals origins and dynamics of monocytes and tissue macrophages under homeostasis. Immunity. 2013;38:79-91.

179. Kleinnijenhuis J, Quintin J, Preijers F, et al. Bacille Calmette-Guerin induces NOD2- dependent nonspecific protection from reinfection via epigenetic reprogramming of monocytes. Proc Natl Acad Sci USA. 2012;109:17537-17542.

180. Yanez A, Hassanzadeh-Kiabi N, Ng MY, et al. Detection of a TLR2 agonist by hematopoietic stem and progenitor cells impacts the function of the macrophages they produce. Eur J Immunol. 2013;43:2114-2125.

181. Mitroulis I, Ruppova K, Wang B, et al. Modulation of haematopoietic progenitors is an integral component of trained immunity. Cell. 2018;172:147-161.

182. Ng RL, Scott NM, Strickland DH, et al. Altered immunity and dendritic cell activity in the periphery of mice after long-term engraftment with bone marrow from ultraviolet- irradiated mice. J Immunol. 2013;190:5471-5484. 
183. Burgess SL, Buonomo $\mathrm{E}$, Carey $\mathrm{M}$, et al. Bone marrow dendritic cells from mice with an altered microbiota provide interleukin 17Adependent protection against Entamoeba histolytica colitis. MBio. 2014;5:e01817.

184. Christ A, Günther $P$, Lauterbach $M$, et al. Western diet triggers NLRP3-dependent persistent functional reprograming of myeloid cells. Cell. 2018;172:162-175.

185. Walachowski S, Tabouret G, Fabre M, Foucras G. Molecular analysis of a short- term model of beta-glucans-trained immunity highlights the accessory contribution of GM-CSF in priming mouse macrophages response. Front Immunol. 2017;8:1089.

186. Park SW, Kaimoyo E, Kumar D, Mosher S, Klessig DF. Methyl salicylate is a critical mobile signal for plant systemic acquired resistance. Science. 2007;318:113-116.

187. Truman W, Bennett MH, Kubigsteltig I, Turnbull C, Grant M. Arabidopsis systemic immunity uses conserved defense signaling pathways and is mediated by jasmonates. Proc Natl Acad Sci USA. 2007;104:1075-1080.

188. Jung HW, Tschaplinski TJ, Wang L, Glazebrook J, Greenberg JT. Priming in systemic plant immunity. Science. 2009;324:89-91.

189. Chaturvedi R, Venables B, Petros RA, et al. An abietane diterpenoid is a potent activator of systemic acquired resistance. Plant J. 2012;71:161-172.

190. Chanda B, Xia Y, Mandal MK, et al. Glycerol-3-phosphate is a critical mobile inducer of systemic immunity in plants. Nat Genet. 2011;43:421-427.

191. Cecchini NM, Steffes K, Schlappi MR, Gifford AN, Greenberg JT. Arabidopsis AZI1 family proteins mediate signal mobilization for systemic defence priming. Nat Commun. 2015;6:7658.

192. Maldonado AM, Doerner P, Dixon RA, Lamb CJ, Cameron RK. A putative lipid transfer protein involved in systemic resistance signalling in Arabidopsis. Nature. 2002;419:399-403.

193. Thevenet D, Pastor V, Baccelli I, et al. The priming molecule betaaminobutyric acid is naturally present in plants and is induced by stress. New Phytol. 2017;213:552-559.

194. Riedlmeier M, Ghirardo A, Wenig M, et al. Monoterpenes support systemic acquired resistance within and between plants. Plant Cell. 2017;29:1440-1459.

195. Pieterse CM, van Wees SC, van Pelt JA, et al. A novel signaling pathway controlling induced systemic resistance in Arabidopsis. Plant Cell. 1998;10:1571-1580.

196. Tassetto M, Kunitomi M, Andino R. Circulating immune cells mediate a systemic RNAi-based adaptive antiviral response in Drosophila. Cell. 2017;169(314-325):e313.

197. Ou J, Li Y, Ding Z, et al. Transcriptome-wide identification and characterization of the Procambarus clarkii microRNAs potentially related to immunity against Spiroplasma eriocheiris infection. Fish Shellfish Immunol. 2013;35:607-617.

198. Kaewkascholkul N, Somboonviwat K, Asakawa S, Hirono I, Tassanakajon A, Somboonwiwat K. Shrimp miRNAs regulate innate immune response against white spot syndrome virus infection. Dev Comp Immunol. 2016;60:191-201.

199. Chen H, Wang H, Jiang S, et al. An oyster species-specific miRNA scaffold42648_5080 modulates haemocyte migration by targeting integrin pathway. Fish Shellfish Immunol. 2016;57:160-169.

200. Beschin A, Bilej M, Torreele E, De Baetselier P. On the existence of cytokines in invertebrates. Cell Mol Life Sci. 2001;58:801-814.

201. Baeza Garcia A, Pierce RJ, Gourbal B, et al. Involvement of the cytokine MIF in the snail host immune response to the parasite Schistosoma mansoni. PLoS Pathog. 2010;6:e1001115.

202. Hanington PC, Brennan $L$, Belosevic M, Andrew KB. Molecular and functional characterization of granulin-like molecules of insects. Insect Biochem Mol Biol. 2008;38:596-603.

203. Naessens E, Dubreuil G, Giordanengo P, et al. A secreted MIF cytokine enables aphid feeding and represses plant immune responses. Curr Biol. 2015;25:1898-1903. 
204. Pila EA, Gordy MA, Phillips VK, Kabore AL, Rudko SP, Hanington PC. Endogenous growth factor stimulation of hemocyte proliferation induces resistance to Schistosoma mansoni challenge in the snail host. Proc Natl Acad Sci USA. 2016;113:5305-5310.

205. Soderhall I, Kim YA, Jiravanichpaisal P, Lee SY, Soderhall K. An ancient role for a prokineticin domain in invertebrate hematopoiesis. J Immunol. 2005;174:6153-6160.

206. Bilej $M$, Joskova $R$, Van den Bergh $R$, et al. An invertebrate TNF functional analogue activates macrophages via lectin-saccharide interaction with ion channels. Int Immunol. 2006;18:16631670.

207. Hibino T, Loza-Coll M, Messier C, et al. The immune gene repertoire encoded in the purple sea urchin genome. Dev Biol. 2006;300:349-365.

208. Roberts S, Gueguen Y, de Lorgeril J, Goetz F. Rapid accumulation of an interleukin 17 homolog transcript in Crassostrea gigas hemocytes following bacterial exposure. Dev Comp Immunol. 2008;32:1099-1104.

209. Wu SZ, Huang XD, Li Q, He MX. Interleukin-17 in pearl oyster (Pinctada fucata): molecular cloning and functional characterization. Fish Shellfish Immunol. 2013;34:1050-1056.

210. Connors VA, de Buron I, Jourdane J, Theron A, Agner A, Granath WO Jr. Recombinant human interleukin-1-mediated killing of Schistosoma mansoni primary sporocysts in Biomphalaria glabrata. J Parasitol. 1998;84:920-926.

211. Yang H, Hultmark D. Tissue communication in a systemic immune response of Drosophila. Fly. 2016;10:115-122.

212. Lamarck J. Philosophie Zoologique, Ou Exposition des Considérations Relatives a L'histoire Naturelle des Animaux. London: Macmillan; 1809.

213. Luna E, Bruce TJ, Roberts MR, Flors V, Ton J. Next-generation systemic acquired resistance. Plant Physiol. 2012;158:844-853.

214. Rasmann S, De Vos M, Casteel CL, et al. Herbivory in the previous generation primes plants for enhanced insect resistance. Plant Physiol. 2012;158:854-863.

215. Slaughter A, Daniel X, Flors V, Luna E, Hohn B, Mauch-Mani B. Descendants of primed Arabidopsis plants exhibit resistance to biotic stress. Plant Physiol. 2012;158:835-843.

216. Kohler A, Schwindling S, Conrath U. Benzothiadiazole-induced priming for potentiated responses to pathogen infection, wounding, and infiltration of water into leaves requires the NPR1/NIM1 gene in Arabidopsis. Plant Physiol. 2002;128:1046-1056.

217. Pavet V, Quintero C, Cecchini NM, Rosa AL, Alvarez ME. Arabidopsis displays centromeric DNA hypomethylation and cytological alterations of heterochromatin upon attack by pseudomonas syringae. Mol Plant Microbe Interact. 2006;19:577-587.

218. Ptashne M. Faddish stuff: epigenetics and the inheritance of acquired characteristics. FASEB J. 2013;27:1-2.

219. Huang CC, Song YL. Maternal transmission of immunity to white spot syndrome associated virus (WSSV) in shrimp (Penaeus monodon). Dev Comp Immunol. 1999;23:545-552.

220. Moret Y. "Trans-generational immune priming": specific enhancement of the antimicrobial immune response in the mealworm beetle, Tenebrio molitor. Proceedings. 2006;273:13991405.

221. Kurtz J, Armitage SAO. Dissecting the dynamics of transgenerational immune priming. Mol Ecol. 2017; 26:3857-3859.

222. Bouts DM, Melo AC, Andrade AL, et al. Biochemical properties of the major proteins from Rhodnius prolixus eggshell. Insect Biochem Mol Biol. 2007;37:1207-1221.

223. Esteves E, Fogaca AC, Maldonado R, et al. Antimicrobial activity in the tick Rhipicephalus (Boophilus) microplus eggs: Cellular localization and temporal expression of microplusin during oogenesis and embryogenesis. Dev Comp Immunol. 2009;33:913-919. 
224. Marchini D, Manetti AG, Rosetto $M$, et al. cDNA sequence and expression of the ceratotoxin gene encoding an antibacterial sexspecific peptide from the medfly Ceratitis capitata (diptera). J Biol Chem. 1995;270:6199-6204.

225. Barribeau SM, Schmid-Hempel P, Sadd BM. Royal Decree: Gene Expression in TransGenerationally Immune Primed Bumblebee Workers Mimics a Primary Immune Response. PLoS ONE. 2016;11:e0159635.

226. Singh NK, Pakkianathan BC, Kumar M, et al. Vitellogenin from the silkworm, Bombyx mori: an effective anti-bacterial agent. PLoS ONE. 2013;8:e73005.

227. Salmela H, Amdam GV, Freitak D. Transfer of immunity from mother to offspring is mediated via egg-yolk protein vitellogenin. PLoS Pathog. 2015;11:e1005015.

228. Freitak D, Schmidtberg H, Dickel F, Lochnit G, Vogel H, Vilcinskas A. The maternal transfer of bacteria can mediate trans-generational immune priming in insects. Virulence. 2014;5:547-554.

229. Knorr E, Schmidtberg H, Arslan D, Bingsohn L, Vilcinskas A. Translocation of bacteria from the gut to the eggs triggers maternal transgenerational immune priming in Tribolium castaneum. Biol Let. 2015;11:20150885.

230. Mukherjee K, Fischer R, Vilcinskas A. Histone acetylation mediates epigenetic regulation of transcriptional reprogramming in insects during metamorphosis, wounding and infection. Front Zool. 2012;9:25.

231. Norouzitallab P, Baruah K, Biswas P, Vanrompay D, Bossier P. Probing the phenomenon of trained immunity in invertebrates during a transgenerational study, using brine shrimp Artemia as a model system. Sci Rep. 2016;6:21166.

232. Asgari S. MicroRNA functions in insects. Insect Biochem Mol Biol. 2013;43:388-397.

233. Harris JF, Micheva-Viteva S, Li N, Hong-Geller E. Small RNAmediated regulation of host-pathogen interactions. Virulence. 2013;4:785-795.

234. Mukherjee K, Grizanova E, Chertkova E, Lehmann R, Dubovskiy I, Vilcinskas A. Experimental evolution of resistance against Bacillus thuringiensis in the insect model host Galleria mellonella results in epigenetic modifications. Virulence. 2017;8:1618-1630.

235. Youngson NA, Whitelaw E. Transgenerational epigenetic effects. Annu Rev Genomics Hum Genet. 2008;9:233-257.

236. Hasselquist $D$, Nilsson JA. Maternal transfer of antibodies in vertebrates: trans- generational effects on offspring immunity. Philos Trans R Soc Lond. 2009;364:51-60.

237. Ho DH, Burggren WW. Epigenetics and transgenerational transfer: a physiological perspective. J Exp Biol. 2010;213:3-16.

238. Audergon PN, Catania S, Kagansky A, et al. Epigenetics. Restricted epigenetic inheritance of H3K9 methylation. Science. 2015;348:132-135.

239. Gaydos L, Wang W, Strome S. Gene repression. H3K27me and PRC2 transmit a memory of repression across generations and during development. Science. 2014;345:1515-1518.

240. Ragunathan K, Jih G, Moazed D. Epigenetics. Epigenetic inheritance uncoupled from sequencespecific recruitment. Science. 2015;348:1258699.

241. Mawa PA, Webb EL, Filali-Mouhim A, et al. Maternal BCG scar is associated with increased infant proinflammatory immune responses. Vaccine. 2017;35:273-282.

242. Naik S, Larsen SB, Gomez NC, et al. Inflammatory memory sensitizes skin epithelial stem cells to tissue damage. Nature. 2017;550:475-480. 


\section{FIGURE 1}

Evolutionary success of innate immune memory. Since LUCA (for Last Universal Common Ancestor), organisms evolved into a couple of major phylogenetic groups: bacteria, plants and animals. Animals can be divided into vertebrates and invertebrates. Ninetynine percent of living organisms are related to invertebrates, plants and microorganisms, while vertebrates represent solely $1 \%$ of such biodiversity. Thus on earth solely $1 \%$ of the organisms possessed an adaptive immunity based on immunoglobulin and clonal selection. Other organisms lack this kind of adaptive immune memory but they met as vertebrates an incredible evolutionary success. This success can be related to the acquisition of a memory capability of the innate immune system that could compensate the lack of classical adaptive immune memory. Innate immune memory or trained immunity appeared as a real evolutionary success that enables all organisms to respond efficiently against pathogen infections

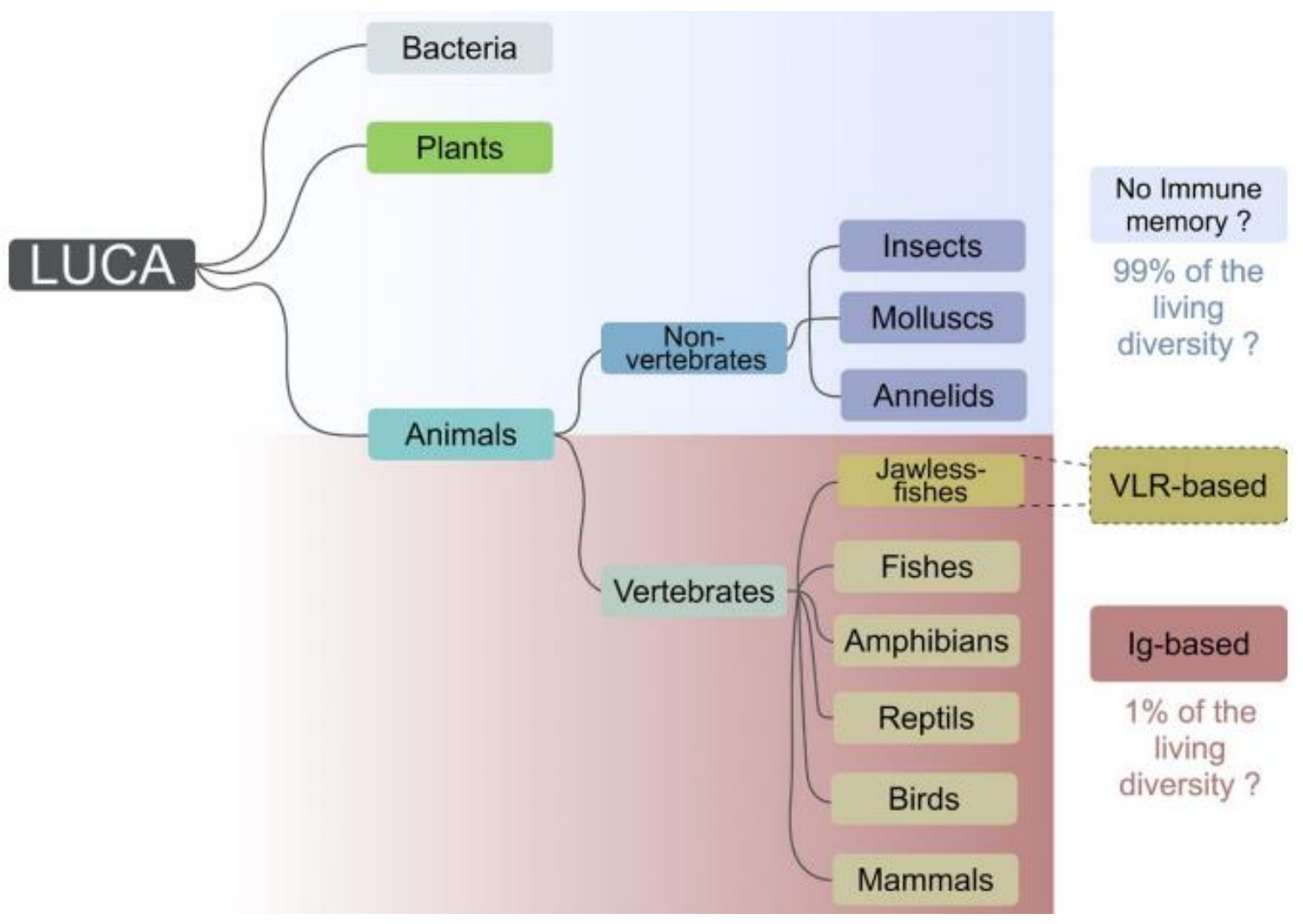




\section{FIGURE 2}

Molecular characteristics of innate immune response shared between bacteria, plants, invertebrates and vertebrates. From prokaryotes, to plants, invertebrates, and vertebrates, some similarities in molecular mechanisms can be particularly pinpointed based on non-exhaustive approaches in the way to sense, acquire and clear an immune response. The activation of primed/trained immunity starts with a naive state (Naive) where cells hold few immune sensors. After activation of immune response (Primed) via several specific surface receptors, the intracellular signals are translated into long-term epigenetic reprogramming, or enhanced levels of PRRs, or accumulation of dormant cellular signaling enzymes of innate immune-specialized cell in animals and essentially all cells in plants. Together, these events provide a memory state of resistance (Trained) that supports deep molecular and metabolic modifications to confer immunity to reinfection in these phylogenetically distant taxa

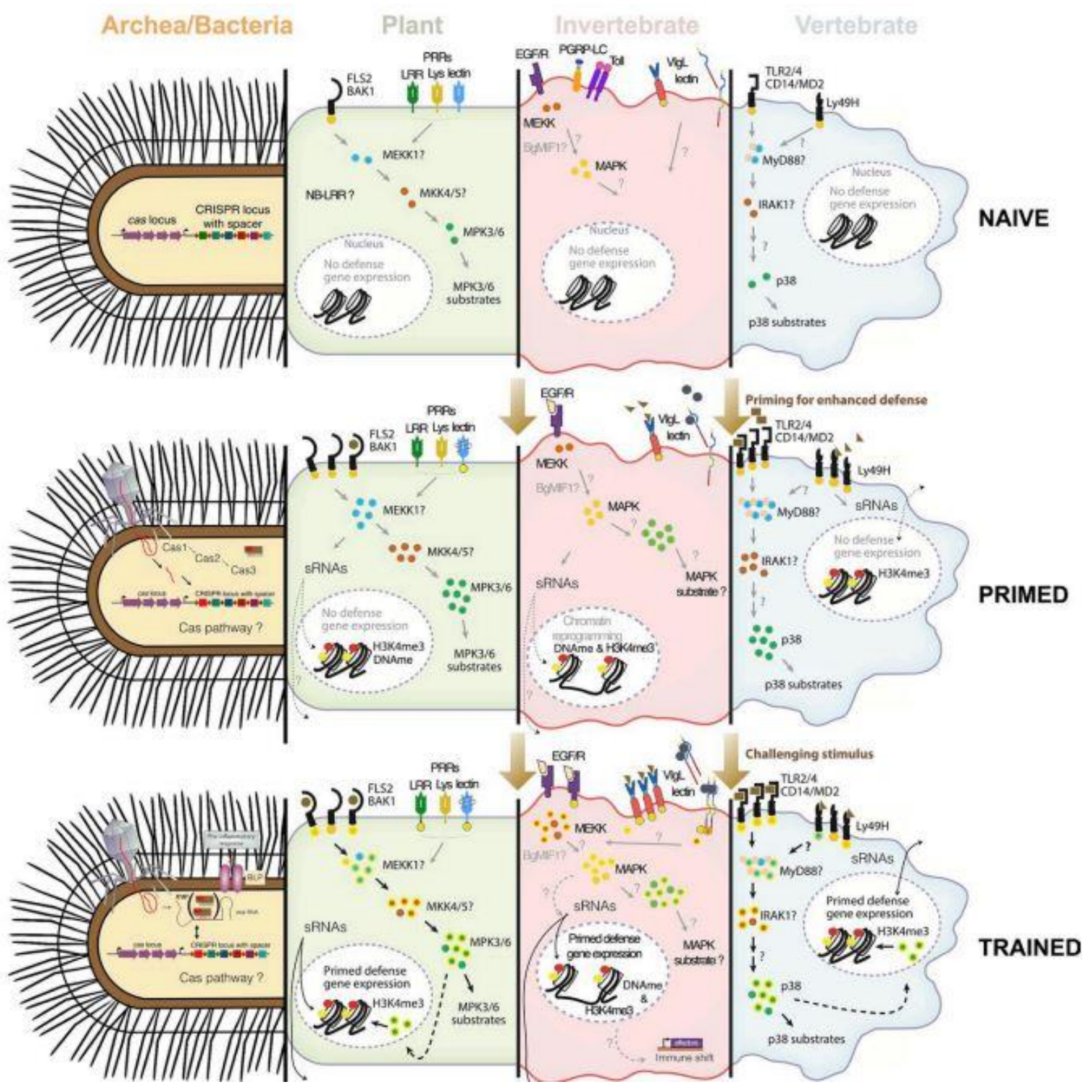




\section{FIGURE 3}

Innate immune memory transmission to progeny. Following primary infection, some living organisms are able to generate a specific and competent immune response with potential memory capacities. Plants and invertebrates undergo epigenetic modifications following infection that support an innate immune memory or trained immunity response. Interestingly, insects and plants are capable of transferring stress-induced epigenetic modifications (histone marks, DNA hypo-methylation) to the next generation and cases of transgenerational immune priming (TGIP) have been described for such organisms. Altogether, these observations lead to the hypothesis that the transfer of epigenetic modifications to the offspring may support trans-generational trained immunity (TGTI) that appeared as an overall general evolutionary process associated with trained immunity or innate immune memory

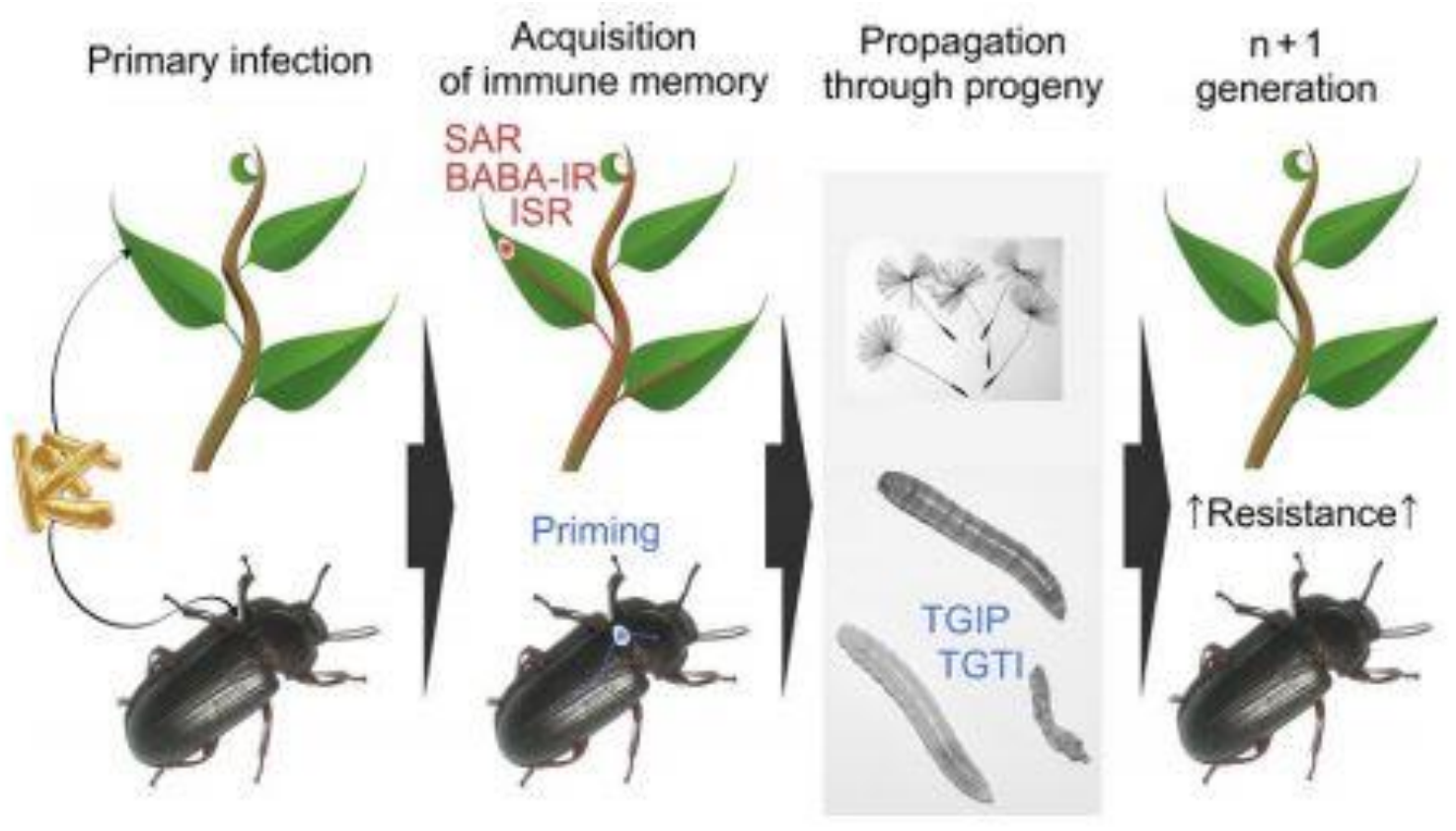




\section{FIGURE 4}

Potential selection through innate immune memory-based resistance during lifespan. Trained immunity enables individuals to acquire enhanced resistance through an innate immune memory pathway. Trans-generational transmission of trained immunity by the off-target reprogramming of germinal cell line suggests a Lamarckian process of resistance able to go through a resistance filter caused by a potential primary infection. Encountering many homologous or heterologous pathogens can activate both Lamarckian and Darwinian resistance acquisition, complementary processes that will finally positively influence the survival of a species. Future works are needed to evaluate the modification of selective values or fitness for $\mathrm{N}+n$ generations following primary encounter with pathogen and activation of trained immunity

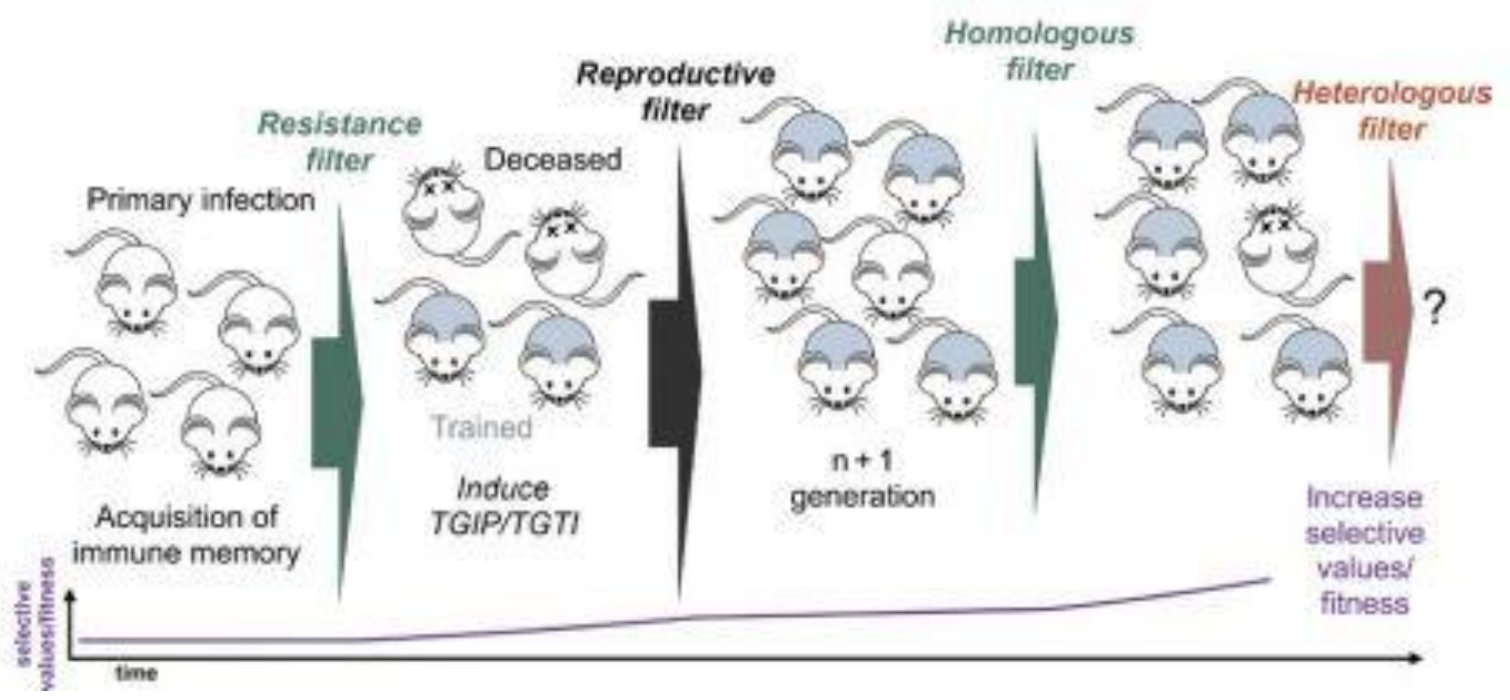




\section{Key concepts of immunological memory}

\section{Immune memory}

Ability of the immune system to store information of a primary infection and to recall the infection for an earlier, sometimes faster, and often more robust response against subsequent exposure to the same or an unrelated pathogen.

\section{Trained immunity}

Long-term enhancement of anti-pathogenic functions within the innate immune host defense after vaccination or infection, which is mediated by metabolic, epigenetic and transcriptional reprogramming of specific innate immune cell populations.

\section{Systemic acquired resistance (SAR)}

State of enhanced defense readiness in plants. SAR is activated upon infection by necrotizing pathogens and establishes throughout the plant. SAR provides unspecific broad-spectrum resistance to (hemi)biotroph microbial pathogens.

Induced systemic resistance (ISR)

State of enhanced defense readiness in plants. ISR establishes upon colonization of the root with growth-promoting rhizobacteria and rhizofungi. ISR is expressed throughout the plant and provides unspecific broad-spectrum resistance to necrotroph microbial pathogens. The spectrum of pathogenic microbes against which ISR provides resistance is nearly, but not completely identical to that of SAR.

\section{Immune/Defense priming}

Activation of the innate immune system following encounter with a dead pathogen, a sub- lethal dose of a live pathogen, a pathogen-associated molecular pattern (PAMP) or an effector of pathogen origin. Immune priming can be associated with a strong protective effect against a subsequent challenge with an otherwise lethal dose of pathogen.

\section{Sustained immune response}

Long-lasting protection against later pathogen challenges that persists even if the pathogen is neutralized. The protection is maintained by the continuous production of relevant immune effectors that can be specific or non-specific regarding the pathogen encountered.

\section{Innate immune tolerance}

State of immunological insensitivity to exogenous (pathogens) and/or endogenous ligands that have the capacity to elicit an immune response in the host. Peripheral tolerance is a key to preventing hypersensitivity of the immune system to various environmental entities, and to limit tissue damage during infection. Tolerance allows for some pathogenic organisms to successfully infect a host and avoid elimination. 